\title{
LA LIBERTAD DE IMPRENTA EN LOS INFORMES MINISTERIALES: COMUNICACIÓN GUBERNATIVA, DINÁMICAS LEGALES Y PERIODÍSTICAS (1821-1867)
}

\author{
Laurence Coudart \\ Universidad Autónoma del Estado de Morelos
}

Drincipio de libertad de imprenta o de prensa, junto con la libertad de pensamiento y de expresión, todos preceptos liberales, se oponen a la censura, específicamente la llamada "censura previa", su antítesis negativa. La abolición inmediata de la licencia previa -es decir, del antiguo régimen de revisión de los textos y de la autorización institucional, previas a la publicación- parece inaugurar una nueva era de libertad. La libertad de imprenta, nuevo derecho imprescindible, es entonces una garantía constitucional, consagrada en todas las actas constitucionales o Cartas fundamentales, desde las Bases de 1822 hasta el Estatuto Imperial de 1865. Sin embargo, en esta primera etapa nacional, la implementación de dicha libertad constituye un problema complejo que no se puede tratar de manera maniquea o esencialista, pues esta cuestión no se reduce a una lucha entre grupos políticos excluyentes considerados de forma simplista progresistas o retrógrados. La libertad de

Fecha de recepción: 30 de julio de 2018

Fecha de aceptación: 17 de septiembre de 2018 
prensa, que acompañó el proceso de independencia y forma parte de su narrativa, corresponde al ideario globalmente compartido por el conjunto de la clase política. Es entonces indisociable de la recién establecida soberanía nacional, el sistema representativo, el principio constitucional y la división de poderes; todos conceptos que, por un lado, remiten a la construcción del inédito Estado nacional y la ardua reorganización o adecuación administrativa y que, por otro, descansan en la formación y la adhesión de la "nación”, así como en un lento e intrincado proceso de transferencias de sacralidades, no exento de contradicciones.

A pesar de declaraciones enfáticas en torno a la libertad de prensa, las relaciones entre clase política y esta última pueden parecer confusas o ambiguas. Ciertamente, en este convulsivo periodo, los vaivenes legales, así como las eternas quejas y discusiones sobre la ilimitada libertad de imprenta, asociada a la desenfrenada "licencia" y la "impunidad" de impresos calificados de "subversivos", "sediciosos", "incendiarios" o “infamatorios”, reflejan los enfrentamientos partidistas, la endémica inestabilidad política e institucional, las tensiones entre los distintos poderes, así como cierto desorden administrativo. También expresan la función social atribuida a la prensa periódica por el conjunto de los grupos políticos. Esta última mirada se relaciona no solamente con la doctrina del contrato social, sino también con la idea de sociedad en tanto que estructura transformable y las modalidades de interacción social, específicamente a través de la producción y la difusión del medio de comunicación entonces en pleno desarrollo: el periódico. Ahora bien, para la clase política de la época, prensa y poder, u "opinión pública” y gobierno, constituyen un binomio, un centro emisor que relega a la sociedad en la periferia; periferia heterogénea cuyas condiciones de integración e intervención en la esfera de comunicación pública dependen en primera instancia de criterios cualitativos: en aquel tiempo la prensa 
no se dirige al "pueblo" sino al "público", vocablos que no se deben confundir. ${ }^{1}$

Todas las sociedades establecen valores sagrados y normas de creencias colectivas que garanticen la vida en comunidad y el lazo social. No es de sorprender que la "censura" haya permanecido en tiempos de libertad declarada, como es el caso, por ejemplo, de la constante defensa de las "buenas costumbres". De igual manera, la construcción del Estado mexicano pasa en sus inicios por la edificación de un consenso nacional. Por tal motivo, la necesidad de arraigar nuevas normas políticas que confieran autoridad al Estado nacional e intenten transfigurar cierta ficción en realidad, aclara la persistencia de la censura de todo lo que cuestiona su legitimidad. Encaja con esta misma lógica la defensa de la religión católica, considerada por muchos como el principal vector de cohesión cultural y nacional. Todas las leyes generales de imprenta, desde la de 1820 hasta la de 1855, además de la ley imperial de 1865, prohíben los ataques a dicha religión; y ello hasta el reglamento de 1861 que, al dejar de contemplar este último "delito" de imprenta, constituye una ruptura. En todo caso y hasta la mitad del siglo, la tolerancia por parte de los poderes civiles de la censura eclesiástica, previa a la edición de obras sobre el dogma y la institución católica, puede considerarse una concesión a la Iglesia, aunque sea sin un real apoyo administrativo.

\footnotetext{
1 Acerca de esta duradera realidad, véase McGowan, Prensa y poder. Enfocándose en la prensa política del periodo 1854-1857, el historiador advierte: “el pueblo no existió para la prensa, ni para el gobierno, ni para el público. Sólo se registró una sociedad de élites, que dictaban sus mandatos al ignorado pueblo. Estas élites estaban constituidas por el público lector de los periódicos y por los miembros de los partidos políticos, cuya máxima recompensa era el ejercicio del poder y el control de la prensa, para salvaguardar al pueblo. En este contexto, la sociedad política viene siendo una tetralogía, cuyos componentes -el poder, la prensa, las élites y los partidos- se conjugan entre sí para crearla, pero siempre con la exclusión del pueblo” (p. 10).
} 
Ahora bien, los fenómenos y las experiencias relacionados con la censura y la libertad de imprenta son múltiples e inestables. Sin profundizar en cada ley o disposición en la materia, el presente estudio tiene como objetivo aclarar las dinámicas generales de elaboración e implementación regulatorias; esto es, explorar e identificar argumentaciones de los discursos ministeriales en tanto que discursos públicos, y confrontarlas con ciertas realidades legales y periodísticas. El análisis descansa, por una parte, en los preámbulos de las leyes generales de imprenta, y sobre todo en las "Memorias" presentadas ante el Congreso por los ministros de Relaciones Interiores y Exteriores, Secretaría de Estado encargada de las cuestiones relacionadas con la libertad de imprenta. ${ }^{2}$ Estos informes no reflejan exclusivamente perspectivas o consignas gubernamentales, sino también precauciones oratorias, referencias y argumentos consensuales, doctrinas o lineamientos programáticos compartidos por los parlamentarios. Al buscar el respaldo y la adhesión de la representación nacional, el ejercicio es también retórico y constituye una verdadera operación de comunicación, pues la aprobación por el Congreso de la Memoria ministerial desemboca en su impresión para su difusión en el público. Se estableció un corpus de 19 memorias de la Secretaría de Relaciones o de Gobernación,

\footnotetext{
${ }^{2}$ Desde los inicios del México independiente, las constituciones, actas o bases constitucionales mexicanas establecen la obligación, para los encargados de los ministerios, de dar cuenta al Congreso del estado en que se hallan los diversos ramos de su secretaría; es decir, presentar anualmente a las cámaras legislativas una memoria sintética y calificadora de la situación y de las acciones del gobierno, en la que el ministro puede proponer iniciativas de ley previamente elaboradas en su despacho. Al formar una sección de la Secretaría de Estado de Relaciones Interiores y Exteriores, la imprenta o la libertad de imprenta son tratadas en todos los informes de este ministerio, que en dos ocasiones se encuentra provisionalmente dividido en dos ministerios distintos, primero en 1837-1841 con la creación por la Constitución de 1836 del Ministerio de lo Interior, y luego en 1853-1861 con la del Ministerio de Gobernación, ministerios independientes que son nuevamente reunidos entre 1861 y 1867.
} 
presentadas ante el Congreso entre 1822 y 1851; las lagunas cronológicas corresponden a la recurrente inestabilidad política $\mathrm{y}$ a las suspensiones del Poder Legislativo. El periodo posterior a 1851 no cuenta con tales informes, sino hasta 1871, cuando el ministro en turno reanuda el ejercicio, años después del regreso de Benito Juárez a la ciudad de México tras la derrota imperial. ${ }^{3}$ Ante estas carencias, varios documentos públicos del gobierno permiten acercarse a las posturas del Poder Ejecutivo.

Por otra parte, se identificaron en compendios de leyes mexicanas decimonónicas y en la prensa periódica, disposiciones reguladoras de la libertad de imprenta, leyes generales de alcance nacional y medidas circunstanciales, cuyo número asciende a 146 entre septiembre de 1821 y agosto de 1867; cifra todavía provisional que excluye las repetidas declaraciones de estado de sitio o de guerra, así como la censura eclesiástica. Entre estas disposiciones, siete (o nueve, si se toman en cuenta textos adicionales sustanciales) corresponden a reglamentos generales, que se multiplican de manera significativa a partir de la década de 1840 . El resto está compuesto por medidas extraordinarias y provisionales, decretos, "bandos", "providencias", “ordenes", “comunicaciones" o circulares, en su mayoría emitidos por el gobierno y que producen, suspenden, rectifican o precisan normas. ${ }^{4} \mathrm{El}$

${ }^{3}$ Los ministros presentaron informe ante el Congreso en los años siguientes: 1822-1823, 1825-1833, 1835, 1838, 1844-1846, 1849-1851. En mayo de 1852, el ministro de Relaciones Interiores y Exteriores leyó su Memoria ante el Congreso, pero solo se publicó un fragmento relacionado con las cuestiones diplomáticas.

${ }^{4}$ Estos distintos términos corresponden a mandatos, dictados de orden superior -en el presente caso del gobierno- y dirigidos a los gobernadores de los estados, y que, si bien no tienen estrictamente fuerza de ley, se deben obedecer, observar y ejecutar, particularmente en tiempos de facultades omnímodas otorgadas al Poder Ejecutivo. De hecho, las definiciones del diccionario de legislación de Escriche, editado en 1837, remiten de manera recurrente al "mandato" de "la autoridad" o del "superior" para aclarar estos términos. Véase Escriche, Diccionario, pp. 68, 132, 205, 222 y 485. En cuanto a las circulares, se refieren a resoluciones reglamentarias del gobierno, igualmente 
gran número de estas disposiciones señala cierta "fiebre" reglamentaria, que puede reflejar la inestabilidad institucional y política pero también dificultades relacionadas con la aplicación del derecho o tensiones entre los distintos poderes, problemas que requieren aclaraciones. Para ello, es necesario establecer las vigencias de las leyes generales de imprenta, así como una periodización comparada de las múltiples disposiciones circunstanciales y la producción periodística. El periodo contemplado, que va desde el Acta de Independencia del Imperio Mexicano hasta los albores de la República Restaurada, se caracteriza por el crecimiento continuo de las publicaciones periódicas, que se multiplican, se diversifican y se modernizan en su forma y su ritmo desde las décadas de 1830-1840. De modo que la edificación del joven Estado y de la sociedad política constituye un proceso enlazado con la construcción del espacio de comunicación social y la ampliación de la esfera pública impresa.

\section{PRINCIPIOS DOCTRINALES, PODERES Y LEYES DE IMPRENTA}

Cuando tocan el tema de la libertad de imprenta, los argumentos de los informes ministeriales permiten vislumbrar dos principios de filosofía política heredados del siglo xviII y postulados en sus orígenes por los británicos John Milton y Jeremy Bentham: la "autocorrección" y el "utilitarismo". El primero de éstos establece que, sin necesidad de legislación regulatoria, la libertad de expresión se autorregula en el "mercado de las ideas" gracias al libre combate entre verdad y falsedad. En esta

dirigidas a los gobernadores, pero no corresponden a un acto administrativo exclusivamente interno; pues, lo mismo que en el caso de los mandatos arriba mencionados, las circulares se publican en la prensa periódica en tanto que órdenes superiores, para el conocimiento del público. Junto con el decreto y la orden, la circular constituye el medio por excelencia del presidente de la República revestido de facultades extraordinarias. 
propuesta, la libertad absoluta de la prensa es un medio que permite la corrección de la falsedad y el triunfo de la verdad. Por su parte, en un sentido moral y político, es decir, en nombre del bien común o general, el principio de utilidad o "utilitarismo" concibe cualquier acción como correcta, siempre y cuando sus consecuencias proporcionan la felicidad o el bienestar colectivo, no individual. En este postulado, donde la libertad es un objetivo, la prensa es socialmente responsable. ${ }^{5}$ Dominante en las Memorias de los ministros mexicanos, el utilitarismo constituye la principal justificación de una necesaria coerción legal que circunscriba y sancione los llamados "abusos" de la libertad de imprenta. Desde el reglamento de 1820, esta última mirada es omnipresente en las leyes generales de imprenta, si bien la terminología es reformada en la ley de 1861, que rechaza la idea de "abuso" del derecho, pero fija "límites" a la libertad de prensa. En todo caso, el interés colectivo prevalece en las concepciones periodísticas de la clase política, que otorgan a la prensa una responsabilidad social por encima del derecho individual. De modo que, en una sociedad considerada inmadura y dirigida por la "opinión pública" de sus élites gobernantes, estas últimas descartan la autorregulación, vista como una fantasía irresponsable o una ilusión lírica. En su lugar, predomina la idea de que la libertad de prensa requiere una regulación específica,

${ }^{5}$ El principio de autocorrección procede del discurso pronunciado ante el Parlamento inglés por John Milton (1608-1674) y publicado en 1644 bajo el título Areopagítica. Un discurso del Sr. John Milton para la libertad de imprenta sin licencia, al Parlamento de Inglaterra. A inicios del siglo xviII, esta obra se difunde con peculiar éxito en las colonias británicas de América, donde triunfa el principio de autorregulación con la primera enmienda a la Constitución de 1787, que descarta todo tipo de ley reguladora de la libertad de expresión y de imprenta. El utilitarismo del británico Jeremy Bentham (1748-1832), revisado posteriormente por su compatriota John Stuart Mill (1806-1873), promueve la libertad de prensa, una libertad relacionada con las prácticas parlamentarias. 
es decir, restricciones y directivas impuestas por el Estado de manera institucional y vertical.

En 1826, Sebastián Camacho, ministro de Guadalupe Victoria, lamenta los abusos y la desenfrenada "licencia" de la prensa, "tropiezos inevitables en la infancia de las naciones", y alega: "Bentham, el defensor más decidido de la libertad de imprenta, dice que deben establecerse trabas contra el abuso, y penas contra los infractores". ${ }^{6}$ En el mismo tenor se expresa su sucesor en el puesto, Juan José Espinosa de los Monteros, quien deplora que "su natural correctivo, que está en la misma libertad", no cuente todavía con "toda la energía que debe recibir de la probidad e ilustrado celo de los literatos mexicanos". Estos últimos, precisa el ministro, "en silencio se duelen" de encontrar en las producciones impresas "tantos motivos de hastío, lástima o tal vez indignación", en lugar de "rasgos de la cultura y talentos de los habitantes de esta floreciente República”. Prosigue Espinosa:

Muchos generosos esfuerzos contra la depravada licencia se ven en otros juiciosos impresos, así como en muy apreciables periódicos se sostiene dignamente la reputación de la ilustración nacional; pero aunque sea grande la corrección que de esto deban esperar las prensas, toca a las leyes definir que la libertad política de la imprenta no es la libertad del pensamiento ni distinta de la que el hombre tiene para decir y obrar, en cuyos actos todas las leyes excluyen lo que ofenda a la sociedad o a un tercero. ${ }^{7}$

Por su lado, José Antonio Romero, ministro en 1838 de Anastasio Bustamante, expone:

[...] mientras estamos en la torpe infancia de la civilización, y en la época peligrosa de afirmar los fundamentos de nuestro ser político,

${ }^{6}$ Ministerio de Relaciones, Memoria, 1826, p. 23.

7 Ministerio de Relaciones, Memoria, 1827, p. 27. 
es necesario que nuestra libertad de imprenta esté tan vigilada y contenida, como la libertad que tiene un niño para andar cuando comienza a ejercer ese derecho natural, a fin de que no tropiece y caiga a cada paso, comprometiendo su salud y existencia. ${ }^{8}$

No faltan ejemplos en los que los ministros, favorables a la necesaria "ilustración” del ignorante "pueblo" y la libertad "política” de la imprenta, afirman la necesidad de contener su “abuso" en nombre de la "utilidad general” y de la "felicidad pública”.

Es también en contraposición al bienestar común que se desacredita a toda clase de oponentes políticos, en particular las "facciones" y los rebeldes levantados en armas, invariablemente retratados como motivados por "pasiones" e "intereses particulares” de corto plazo, antítesis del interés colectivo. Ante las luchas partidistas, las incesantes revoluciones y las amenazas extranjeras, numerosos son los gobiernos que declaran que la prensa política, siempre impune, es responsable del caos y de la fragilidad del Estado. Si bien en ello se vislumbra una estrategia política para ampliar las competencias del Poder Ejecutivo y eventualmente justificar el autoritarismo y la represión, es preciso reconocer que el principio de autocorrección o autorregulación periodística es inaudible y probablemente inoportuno en este contexto. Este principio, evocado en el Congreso Constituyente de 1856-1857, se encuentra postulado en la declaración de Zarco, según la cual "para la imprenta no hay mejor correctivo que el de la misma imprenta"; 9 sentencia que reitera en múltiples ocasiones, en particular en El Siglo Diez y Nueve. Sin embargo, la ley de imprenta presentada ante el Constituyente y firmada por Zarco reconoce "límites" a la libertad de imprenta, es decir, "el respeto a la vida privada, a la moral y a la paz pública",

${ }^{8}$ Ministerio de Relaciones, Memoria, 1838, p. 14.

9 Sesión del 3 de febrero de 1857, en Zarco, Historia, t. II, p. 903. 
límites los menos drásticos y numerosos del siglo, pero todavía restrictivos y vagos. La paradoja de la postura se encuentra toda en las distintas declaraciones del legislador-periodista Zarco, quien en 1856 reconoce en el Constituyente: "convengo en que el bien de la sociedad exige ciertas restricciones para la libertad de la prensa"; pero, en enero de 1861, ahora en tanto que ministro de Relaciones del gobierno de Juárez, anuncia la implementación de la nueva legislación de imprenta -con sus limitantes-y de nuevo afirma: "El gobierno [...] cree que sus abusos tienen su correctivo en la misma imprenta". ${ }^{10} \mathrm{Al}$ fin y al cabo, después del triunfo de la república liberal en 1867-1868, el principio de autocorrección, integrado y reiterado por distintos gobiernos, parece reducirse a una fórmula piadosa.

De hecho, el predominio del principio utilitarista que limita la libertad de prensa, entra en conflicto con las garantías constitucionales de los derechos individuales, establecidas en casi todas las cartas fundamentales y particularmente explícitas en la Constitución de 1857, que dedica en la primera sección de su Título I no menos de 29 artículos a los "derechos del hombre". ${ }^{11}$ Esto es, libertad de opinión o de pensamiento, libertad de ex-

10 Véase la declaración de Zarco en el Constituyente, sesión del 25 de julio de 1856, en ZARCO, Historia, t. I, p. 743, y su circular dirigida a los gobernadores de los estados, con fecha del 20 de enero de 1861, en El Siglo Diez y Nueve, 31 de enero de 1861, p. 2.

${ }^{11}$ La Constitución de 1824 no menciona derechos o garantías individuales, pero su artículo 50 (conservado en el Acta de Reformas de 1847) estipula que "proteger y arreglar la libertad política de imprenta" es una de "las facultades exclusivas del Congreso general”, "de modo que jamás se pueda suspender su ejercicio, y mucho menos abolirse en ninguno de los Estados ni territorios de la federación". La Primera Ley Constitucional de 1836 define en quince artículos los "derechos y obligaciones de los mexicanos", mientras que las Bases Orgánicas de 1843 establecen en el artículo 9 de su Título II los "derechos de los habitantes de la República”. El Estatuto Provisional del Imperio Mexicano de 1865 dedica su Título XV y veinte artículos a "las garantías individuales" (artículos 58-77). Véase Tena Ramírez, Leyes, pp. 174, 205-208, 406-408, 607-611 y 678-679. 
presión y de prensa. En cuanto a la calificación del derecho, resulta significativa la referencia -en los inicios del periodo-a la "libertad política de la imprenta", que parece privilegiar el derecho constitucional o positivo -político e institucional-, en detrimento del filosófico o "metafísico" derecho natural, de carácter más inmutable que las cambiantes constituciones. Recurrente desde 1810, tal apreciación exclusivamente "política" tiende a desaparecer de los textos legales y discursos oficiales desde la década de 1830. En todo caso, el antagonismo entre la limitación de la libertad y las garantías individuales, junto con la cuestión de la constitucionalidad de los proyectos de ley, generan largos y polémicos debates en la representación nacional, cuyas controversias y tergiversaciones jurídicas son esencialmente predeterminadas por criterios morales o ideológicos, sin realmente desembocar en la elaboración de un derecho aplicable. A menudo, los informes ministeriales presentan precauciones oratorias, al mencionar la libertad del pensamiento que siempre dicen respetar, no sin enfatizar contradicciones con la necesidad de garantizar la "tranquilidad pública", la obediencia a las autoridades y la reputación de los funcionarios públicos, es decir, el respeto y la legitimidad del gobierno; todas consideraciones que dan cuenta de lógicas opuestas, de tensiones entre Poder Ejecutivo y Poder Legislativo, de cuestiones de distribución y de equilibrio constitucionales de sus competencias. Sea como fuere, estas instancias son particularmente inestables, por las elecciones que modifican su composición, los golpes de Estado y los cambios de regímenes; una inestabilidad que genera inconstancia y versatilidad respecto de las normas reguladoras de la libertad de imprenta, normas propuestas con frecuencia por el gobierno.

Entre 1824 y 1855, advierte la historiadora Linda Arnold, el Poder Judicial es "la rama más estable, prestigiosa e influyente del gobierno"; en particular por la integridad, la autonomía respecto del juego político y la longevidad de los integrantes de 
la Suprema Corte de Justicia, vitalicios hasta 1855 , cuando tiene lugar la reestructuración de esta instancia. ${ }^{12}$ No obstante, la constitucionalidad de las leyes y su adecuación con los derechos individuales no competen al Poder Judicial, sino al Congreso federal con base en la Constitución de 1824, y, luego, al Supremo Poder Conservador, "cuarto poder" instaurado por las Leyes Constitucionales de 1836, hasta su desaparición consumada en las Bases de 1843. Si bien en este periodo interviene la Suprema Corte, siempre es con base en una competencia exclusivamente consultiva, pues no emite sentencias revocatorias, prerrogativa del "cuarto poder", que en reiteradas ocasiones neutraliza las iniciativas gubernamentales. En este marco jurídico se inscriben los distintos dictámenes de la Suprema Corte relativos al ejercicio y la conservación de la libertad de opinión y de prensa. Por ejemplo, cuando, consultada por la Cámara de Diputados, la Corte dictamina negativamente en 1839 y nuevamente en 1840 dos iniciativas gubernamentales de ley de imprenta, porque -precisan los dictámenes-, sin contentarse con las represivas, buscan establecer medidas "preventivas", es decir, una suerte de censura previa que anula el derecho. De nuevo, los años de 1840-1850 resultan centrales en la dinámica general. En ciernes desde la década de 1840, en particular desde el Acta de Reformas de 1847, el juicio de amparo -instituido por la Constitución de 1857- convierte a la Suprema Corte de Justicia en el garante federal de los derechos individuales. Esta evolución asienta la primacía de las garantías constitucionales a nivel federal y de la autoridad central por encima de la autonomía de los estados,

12 En las décadas de 1820 y 1830, la Suprema Corte de Justicia realiza una obra monumental, al reorganizar la justicia e intentar resolver el embrollo de la supervivencia del corpus jurídico colonial; ello, sin reglamentos precisos, en un "frenesí de actividad organizativa y política". Nombrados por el Poder Ejecutivo a partir de 1855, los ministros de la Suprema Corte luego son electos, en virtud de la Constitución de 1857, y se vuelven dependientes de las contiendas partidistas. Véase Arnold, Política, pp. 14, 48-49. 
pero también fortalece cierta independencia del Poder Judicial. ${ }^{13}$ Tal tendencia a la centralización político-administrativa se refleja en los discursos ministeriales, cuyas variaciones señalan inquietud por dominar o neutralizar los procedimientos jurídicos específicos en materia de libertad de imprenta; tendencia que igualmente se observa en las modalidades de implementación de normas reguladoras de la imprenta.

Desde la década de 1820, y con notable constancia, los informes ministeriales se quejan de la ineficiencia judicial respecto de los delitos de prensa, al denunciar sin cesar los abusos y la impunidad de los infractores. Éstos resultan, dicen los ministros, de la inadecuación de los reglamentos específicos, así como del sistema de jurados y de fiscales de imprenta, que generan lentitud y desaciertos. De por sí, el "Reglamento adicional para la libertad de imprenta" de 1821 tiene por objeto acelerar los juicios por delitos de imprenta, mientras que el decreto de 1828 , igualmente enfocado en los procedimientos judiciales, revisa la ley general de imprenta de 1820 y rectifica los criterios de los nombramientos de los jurados. ${ }^{14}$ Particularmente significativo

13 Acerca de estas dinámicas, véase GonZÁLEz, “Las transiciones”, pp. 111114, y Andrews, De Cádiz, pp. 166-169.

${ }^{14}$ Los considerandos del "Reglamento adicional" de 15 de diciembre de 1821 denuncian "la morosa lentitud con que se ha procedido en la calificación de algunos escritos denunciados, cuyos autores aún no han sufrido el castigo que la ley les señala"; asimismo, indican que se trata de "abreviar y facilitar los trámites de los juicios sobre abusos de la libertad de imprenta, con el objeto de que el pronto castigo del culpado retraiga de imitarle a los que no contiene el amor al orden y a su Patria”. Por su lado, el decreto de 14 de octubre de 1828 establece en su artículo 4 que para fungir como jurados de imprenta, los ciudadanos deben tener "un capital de cuatro mil pesos para arriba, o una industria u oficio que les produzca cuatrocientos pesos anuales en los territorios, mil en el distrito, y de seiscientos para arriba a juicio de las legislaturas en los estados"; notable cambio en el nombramiento de los jurados, pues la ley de 1820 no contempla requisitos financieros. Véase Dublán y Lozano, Legislación, t. I, 1876, núm. 259, pp. 564-565, y t. II, 1876, núm. 585, pp. 81-82. 
es el discurso de Lucas Alamán, quien, en 1830, lamenta amargamente los efectos contraproducentes del mecanismo jurídico:

[...] las demoras que se experimentan en la reunión del jurado por la mucha repugnancia con que los individuos que deben componerlo concurren, dan todo el tiempo necesario para que se haga nueva edición del papel acusado, que en el hecho de estarlo, excita la curiosidad y se fomenta el expendio, de suerte que cuando llega el caso de mandarlo recoger, esta medida es enteramente ilusoria.

El ministro concluye: "Yo me abstendré de indicar remedio alguno para este mal de que se encargará también el Sr. Secretario de Justicia, y que la sabiduría del Congreso sabrá contener" ${ }^{15}$ En realidad, Alamán ataca a la vez el sistema de jurados de imprenta y la existencia misma de un reglamento específico para la libertad de imprenta. Así lo señala de manera explícita el periódico oficial -bajo la autoridad del ministro-, al declarar una semana después del informe ministerial que "reglamentar aisladamente sobre la imprenta" desvirtúa los juicios, que "la imprenta no es más que un instrumento de delinquir como otro cualquiera" y que "es absurdo un código particular para reprimir los delitos" de prensa. ${ }^{16}$ En enero de 1831, el mismo Alamán de nuevo solicita en su Memoria providencias contra los abusos que quedan todos subsistentes, mientras que nuevamente el periódico oficial apunta que "el único origen de ellos es la falta de leyes claras que establezcan penas proporcionadas a los crímenes y aseguren su imposición por medio de trámites sencillos y rápidos". ${ }^{17}$ Es en toda lógica que la ley contra los "libelos infamatorios", decretada por el Congreso el 14

15 Ministerio de Relaciones, Memoria, 1830, pp. 23-24.

${ }_{16}$ Registro Oficial del Gobierno de los Estados-Unidos Mexicanos, 20 de febrero de 1830, pp. 120-121.

17 Registro Oficial del Gobierno de los Estados-Unidos Mexicanos, 1 de febrero de 1831, p. 128. 
de mayo de 1831, descarta los jurados para esta clase de delitos -jurados que dejarán de funcionar durante varios años- y establece procedimientos ante los tribunales comunes. Asimismo, la Constitución de 1836 estipula que los abusos de la libertad de imprenta quedan "en la clase de delitos comunes", pero, "con respecto a las penas, los Jueces no podrán excederse de las que imponen las leyes de imprenta, mientras tanto no se dicten otras en esta materia". ${ }^{18}$ Este último intento resulta finalmente frustrado, pues genera hasta septiembre de 1841 -cuando cesa la vigencia de la Constitución de 1836- una multitud de consultas por parte de los jueces de letras sobre la manera de interpretar el desconcertante mandato constitucional. Por su parte, el jurado de imprenta conoce una vigencia reglamentaria intermitente, en particular durante los periodos de emergencia, y si parece triunfar en las normas regulatorias es también perdiendo esferas de competencia. ${ }^{19}$

Cabe subrayar que la estrategia que consiste en descartar los jurados -nombrados por los ayuntamientos- busca depositar los juicios de imprenta en las únicas manos del sistema judicial. En cualquier caso, con o sin jurado, las denuncias de los

18 Primera Ley Constitucional, artículo 2, fracción VII, en Tena Ramírez, Leyes, p. 206. En 1838, el ministro José Antonio Romero claramente desea radicalizar esta lógica, al preguntar: “¿por qué [la libertad de escribir] no se ha de sujetar como los demás derechos y libertades del hombre en sociedad a las severas y comunes leyes de una sabia y rigorosa policía?”; MINISTERIO DE Relaciones, Memoria, 1838, p. 13.

19 El reglamento general de libertad de imprenta de 1846 restablece el juicio por jurados, "principal garantía de la libertad de imprenta". En 1847, el Acta de Reformas excluye la intervención de los jurados en los delitos de difamación; lineamiento que ratifica la Ley Otero de 1848, enteramente dedicada a esta clase de delitos. Por su lado, la represiva Ley Lares de 1853 no contempla procesos judiciales, sino exclusivamente condenas gubernativo-administrativas (además de los eventuales delitos comunes que competen a los tribunales ordinarios). Por ende, la ley de 1855 suprime los jurados, hasta su restitución en la Ley Zarco de 1861; esta última siendo sustituida por la anterior en periodos de "facultades extraordinarias" del Poder Ejecutivo. 
impresos pueden ser iniciativas individuales o bien del síndico del ayuntamiento, o sobre todo del fiscal de imprenta a quien los impresores deben enviar el conjunto de su producción. Esta última figura es entonces fundamental, sobre todo por las modalidades de su nombramiento y en consecuencia por su eventual dependencia respecto de los poderes Legislativo o Ejecutivo. Nombrado “por la diputación provincial” en la ley de 1820, el fiscal de imprenta lo es por el supremo gobierno en el Distrito Federal, los gobernadores en los estados y "la primera autoridad política” en las demás partes, según el decreto de 1828. Pero tal intervención gubernativa desaparece cuando quedan reducidos los delitos de imprenta a la clase de comunes por la Constitución de 1836, la que igualmente reduce los reglamentos de imprenta a su parte penal. Por ello, en 1838, el ministro José Antonio Romero interpela -en vano- al Congreso para que expida un nuevo reglamento ajustado a las leyes constitucionales. ${ }^{20}$ En 1846, nuevo cambio: el reglamento de imprenta ratifica el deseo en todo opuesto al anterior, y neutraliza las intrusiones gubernativas al establecer que procederán al nombramiento del fiscal de imprenta el congreso general en el distrito, las legislaturas en los estados y los ayuntamientos de las capitales de los territorios. Los retos de esta batalla jurídica son así expresados, en 1850 y 1851, por el ministro José María de Lacunza, quien recalca que "lo que hoy urge más, y de más expedita resolución, es el nombramiento de los fiscales de imprenta”, y declara:

20 Romero argumenta: "han cesado los fiscales de imprenta, y la vindicta pública está librada a la oficiosidad de los jueces, que como no tienen concedido el derecho de que les pasen un ejemplar de todos los impresos antes de circularlos, muchas veces ignoran los delitos [...]. El Gobierno [...] no tiene otro arbitrio legal para impedir o contener los males causados por los abusos de la imprenta, que hacer excitativas a los tribunales, cuyos procedimientos son necesariamente tardíos"; Ministerio de Relaciones, Memoria, 1838, p. 13. 
$[\ldots]$ el gobierno [...] no puede influir ni aun sobre los fiscales de imprenta, sino por excitaciones frecuentemente desatendidas; y en consecuencia de esta poca acción represiva del ejecutivo, la imprenta es hoy un órgano de ataque a las personas y a las instituciones. [...] al gobierno mismo se le ha imputado debilidad o tolerancia, sin atender que a fuerza de exagerar el principio liberal, de que la imprenta sirva contra los funcionarios públicos, se ha privado a éstos casi de toda acción sobre ella. ${ }^{21}$

En todo caso, es a partir de la década de 1850 que los reglamentos de libertad de prensa refrendan la intromisión gubernativa en los procesos judiciales: desde la ley de 1853 que suprime los juicios específicos de prensa -sustituidos por procedimientos gubernativo-administrativos directos- pero restaura el fiscal de imprenta, esta vez nombrado por los gobernadores en el Distrito Federal y los estados, y los jefes políticos en los territorios; pasando por la ley de 1855 que restablece el juicio pero suprime el jurado de imprenta, y reproduce las mismas modalidades que la ley anterior para el nombramiento del fiscal (con excepción del Distrito Federal, cuyo fiscal de imprenta es nombrado por el gobierno general); hasta la ley de 1861 que restablece los jurados pero suprime la figura del fiscal de imprenta, entonces sustituida por la del "ministerio fiscal”, en este año y en virtud de facultades extraordinarias del Poder Ejecutivo, nombrado en el distrito por el presidente Juárez.

Tal evolución de los vaivenes legales en torno a la intervención gubernativa va de la mano con el carácter provisional de la regulación de la prensa, por una parte, y, por otra, con la

21 Ministerio de Relaciones, Memoria, 1850, pp. 46-47 y 49. Al año siguiente, el mismo ministro lamenta: “[el ejecutivo] al cuerpo legislativo, le pidió un remedio suavísimo, tal vez insuficiente, que consistía en dejar a los fiscales de imprenta más dependientes del gobierno de lo que ahora lo son: las cámaras no tuvieron a bien atender a esta idea"; Ministerio DE RELACIONES, Memoria, 1851, p. 26. 
naturaleza autoritaria o centralizadora de las leyes de imprenta. Entre las siete grandes normatividades significativas, instauradas entre 1821 y 1867, solo una se declara “orgánica” con base en el derecho español. Esta es la ley española de 22 de octubre-12 de noviembre de 1820 , votada por las Cortes y sancionada por el rey de España, oficialmente vigente en México desde el 18 de octubre de 1821. Es complementada o enmendada por el "Reglamento adicional para la libertad de imprenta" de 15 de diciembre de 1821 que la adecua con "la Constitución del Imperio" y por el decreto de 14 de octubre de 1828, arriba mencionados; dos textos que retocan la nutrida ley general de 1820 y cuya vigencia corre paralela con esta última. ${ }^{22}$ Esta normatividad, sustituida por el reglamento de 1846, es así la más longeva del periodo. Desde 1846, todas las reglamentaciones generales, en principio arrimadas a las inestables y temporales cartas fundamentales, “estatutos” y otras "bases orgánicas” (con excepción del reglamento de 1853), descansan en "considerandos” apremiantes y circunstanciales, y son explícitamente provisionales, incluso la Ley Zarco de 1861, "reglamento provisorio" suspendido casi de inmediato y publicado en tanto que "ley orgánica” solo el 4 de febrero de 1868. De modo que impera cierto caos jurídico, aún más cuando raramente se derogan explícitamente las normas generales ni las medidas de excepción, que se entrelazan y ocasionalmente se contradicen. Por lo regular, se considera que las "revoluciones" nulifican de hecho las reglamentaciones anteriores, pero en reiteradas ocasiones los debates periodísticos

${ }^{22}$ El reglamento adicional de 15 de diciembre de 1821 es establecido por decreto de la Soberana Junta Provisional Gubernativa del Imperio Mexicano. La ley de 14 de octubre de 1828, que sustituye el título VII de la ley de 1820 sobre el modo de proceder en los juicios de imprenta, corresponde a un decreto del Congreso, establecido "ínterin se concluye el reglamento de imprenta". Estas disposiciones se encuentran incluidas en reglamentos generales posteriores, en particular la Ley Lafragua de 1846 que incorpora partes sustanciales de la ley de 1828. Véase Dublán y Lozano, Legislación, t. I, 1876, núm. 259, pp. 564567 (reglamento de 1821) y t. II, 1876, núm. 585, pp. 81-86 (decreto de 1828). 
expresan conjeturas o sumos desconciertos respecto de la norma vigente. ${ }^{23}$

Por otra parte, el conjunto de las leyes generales de imprenta, sin excepción, se implementa no por la votación del Congreso, sino por decisión unilateral del gobierno y en virtud de amplias “facultades extraordinarias” del Poder Ejecutivo (véase el cuadro en el Anexo). Impuestas por el gobierno gracias a poderes de excepción, las normatividades generales, o bien fueron elaboradas por el ministerio, sin descansar en antecedentes parlamentarios, o bien corresponden a proyectos debatidos, pero no votados por el Congreso. La ley española de 1820 se impone, sin consulta previa, mediante un decreto de la Soberana Junta Provisional Gubernativa del Imperio Mexicano. La ley liberal de 14 de noviembre de 1846 (primera Ley Lafragua), decretada por el gobierno del general José Mariano Salas, fue aprobada en 1845 en la Cámara de Diputados, con base en propuestas de una comisión, pero no discutida en la de Senadores. El decreto del gobierno de 21 de junio de 1848 (Ley Otero) es elaborado y expedido por Mariano Otero, ministro de Relaciones del general José Joaquín de Herrera, presidente constitucional, al finalizar la guerra con Estados Unidos y en un periodo de receso del Congreso. El decreto del gobierno de 25 de abril de 1853 (Ley Lares) se implementa en los inicios de la dictadura del general Antonio López de Santa Anna, quien declaró en receso las legislaturas. El reglamento de 28 de diciembre de 1855, firmado por José María Lafragua, es decretado por el gobierno de Ignacio Comonfort en virtud de las “amplias facultades" concedidas al presidente interino por el Plan de Ayutla de 1854. De hecho, esta normatividad revisa en un sentido más represivo la primera Ley Lafragua, respetando así -precisa el ministro- el deseo del

23 Solo dos reglamentos generales de imprenta precisan que derogan los textos anteriores: la ley de 1820 cuyo artículo 83 anula todos los decretos anteriores sobre la libertad "política" de imprenta, y la Ley Lares de 1853 cuyo artículo 50 suprime el reglamento de 1848. 
presidente Comonfort "de combinar la libertad con el orden", y forma la principal base de la ley imperial de 10 de abril de 1865, firmada por el ministro de Gobernación José María Cortés y Esparza. ${ }^{24}$ Por ende, la Ley Zarco de 2 de febrero de 1861 corresponde al "proyecto de ley orgánica" elaborado por Francisco Zarco, Guillermo Prieto y Rafael González Páez, presentado en el Congreso Constituyente el 13 de enero de 1857 y debatido en las sesiones de 3 y 4 de febrero; Congreso que se separa el 17 de febrero de 1857 sin haberlo votado. ${ }^{25}$ Al finalizar la Guerra de Tres Años y a tres meses de la reunión del nuevo Congreso, la ley es decretada por el gobierno de Benito Juárez en virtud de facultades extraordinarias.

Las normatividades son así verdaderos dispositivos que buscan efecto práctico e inmediato. Aunado a ello, la ampliación de las competencias del Ejecutivo permite evadir los debates parlamentarios, así como la eventual inconstitucionalidad de textos que maltratan las garantías individuales. Inauguradas en 1829, durante la presidencia de Vicente Guerrero, las facultades extraordinarias del Ejecutivo, autorizadas por el Congreso, pero no plasmadas en la Constitución de 1824, son en consecuencia extra constitucionales, y ello hasta las Bases Orgánicas de 1843 que, por primera vez, introducen en el derecho positivo facultades de excepción y de emergencia en los casos de invasión o de sedición "grave". Sin embargo, el restablecimiento en 1846 de la Constitución de 1824 y el Acta de Reformas de 1847 significan el retorno a la situación anterior. Por su lado, los repetidos pronunciamientos otorgan idénticas amplias facultades a su "campeón" para imponer y suprimir normas en todos

\footnotetext{
${ }^{24}$ Acerca de la Ley Lares de 1853 y sobre todo de la Ley Lafragua de 1855, que inspiran la ley imperial de 1865, véase COUDART, "La regulación".

${ }^{25}$ La sesión del Congreso Constituyente del 4 de febrero de 1857, última en la que se debate el proyecto de ley, concluye: "Suficientemente discutido el proyecto en general, se pregunta si ha lugar a votar; pero resulta que no hay quorum, y se disuelve la reunión"; ZARCO, Historia, t. II, p. 910.
} 
los ramos de la administración pública. Es en buena lógica y con cierto radicalismo que el giro constitucional de 1843 se encuentra confirmado en la Constitución de 1857. Esta última instituye la suspensión de garantías, que -previa aprobación del Congreso- solo el presidente puede implementar "por medio de prevenciones generales". ${ }^{26}$ Así, el decreto del Congreso de 3 de noviembre de 1857, que declara la suspensión de garantías, estipula: "El Ejecutivo dictará los reglamentos y órdenes relativas a dicha suspensión en todos los casos en que deba tener efecto". El 5 de noviembre siguiente, el gobierno de Ignacio Comonfort establece como primera de sus "prevenciones" la sujeción de la libertad de imprenta a la segunda Ley Lafragua de 1855, así como la institución de la represión gubernativa directa-que puede "prevenir el fallo judicial"- contra los autores e impresores de escritos "que directa o indirectamente afecten la Independencia nacional, las instituciones o el orden público". ${ }^{27}$ Esta prevención, que asienta la preeminencia de la ley de 1855 en tiempos de excepción y elude el Poder Judicial, constituye la matriz del decreto de suspensión de garantías de 7 de junio de 1861, refrendado en la República de Juárez en 1861, 1862, 1863 y

${ }^{26}$ El artículo 29 de la Constitución de 1857 autoriza la suspensión de garantías "en los casos de invasión, perturbación grave de la paz pública, o cualesquiera otros que pongan a la sociedad en grande peligro o conflicto". Las Bases Orgánicas de 1843 otorgan al Congreso la facultad de "Ampliar las facultades del Ejecutivo con sujeción al artículo 198 en los dos únicos casos de invasión extranjera, o de la sedición tan grave que haga ineficaces los medios ordinarios de reprimirla" (artículo 66). El artículo 198 estipula: "Si en circunstancias extraordinarias la seguridad de la Nación exigiere en toda la República, o parte de ella, la suspensión de las formalidades prescritas en estas bases, para la aprehensión y detención de los delincuentes, podrá el Congreso decretarla por determinado tiempo". Tena Ramírez, Leyes, pp. 415, 435 y 610.

${ }^{27}$ Decretos de 3 y 5 de noviembre de 1857, Dublán y Lozano, Legislación, t. VIII, 1877, núm. 5017, pp. 645-646. El gobierno y los gobernadores de los estados pueden imponer, sin juicio previo, multas de mil pesos y penas de prisión hasta de por seis meses. 
1865. De modo que se enraíza la represión gubernativa, práctica institucionalizada por la Ley Lares en 1853.

Tal concentración "excepcional” de poderes en el Ejecutivo y la suspensión del estado de derecho tienden entonces a convertirse en el modus operandi del gobierno que, autorizado o no por el Congreso o el derecho constitucional, sobrepasa con frecuencia su esfera de competencia. Bajo el régimen republicano, se registran 26 decretos y pronunciamientos otorgando "facultades extraordinarias" amplias u "omnímodas" al Poder Ejecutivo; un procedimiento particularmente vivaz entre 1841 y 1867 , cuando estos decretos están vigentes durante dos terceras partes $(66 \%)$ del periodo. ${ }^{28}$ La primacía del control de la prensa se puede observar en las primeras medidas instauradas por los gobiernos revestidos de facultades amplias. Así, por ejemplo, las inaugurales facultades extraordinarias concedidas por decreto del Congreso de 25 de agosto de 1829 desembocan inmediatamente en los decretos de 4 y 11 de septiembre de 1829 que establecen la responsabilidad conjunta de los autores, editores e impresores, así como procedimientos gubernativos en su contra. En esta suerte de "golpe de Estado" permanente en pro del Poder Ejecutivo, que convierte la excepción en norma, no es de extrañar el gran número de disposiciones establecidas durante el periodo. De hecho, entre las 146 identificadas, 125 $(86 \%)$ son iniciativas del gobierno y solo 21 (14\%) son decretos del Congreso: más de la mitad de estos últimos votados antes de 1836. En términos cronológicos, la década de 1820 y los inicios de la década siguiente aparecen como un periodo de ajustes reglamentarios y de experimentaciones gubernativas en tiempos de crisis (véase la gráfica 1 en el Anexo). La evolución general

${ }^{28}$ Entre estos 26 decretos, 19 (73\%) son “extraconstitucionales” o revolucionarios; proporción que se reduce a $42 \%$ del conjunto si no se toman en cuenta los pronunciamientos. Del conjunto, 14 son votados por el Congreso (de los que 7 son extra-constitucionales, votados entre agosto de 1829 y enero de 1853), 8 son de pronunciamientos exitosos y 4 del Poder Ejecutivo. 
señala nuevamente los años de 1840, que inician un largo ciclo de "fiebre" regulatoria hasta incluso el Segundo Imperio. Es preciso señalar que el espectacular crecimiento del periodo 18611865 se debe en parte al antagonismo y la coexistencia de los dos gobiernos del presidente Juárez y del emperador Maximiliano. No cabe duda que los vaivenes regulatorios reflejan la constante atención de las autoridades políticas respecto de la prensa y las reiteradas secuencias revolucionarias -en particular desde las décadas de 1840-1850-, así como la creciente centralización y preeminencia federal en materia de libertad de imprenta. En realidad, el crescendo reglamentario va de la mano con la represión gubernativa directa, sin observancia del procedimiento judicial $\mathrm{o}$ independientemente de las autoridades judiciales, y con poco respeto por las garantías constitucionales, con frecuencia suspendidas. Con todo, tal "respiración" cronológica también da cuenta del potente desarrollo periodístico.

\section{“CIVILIZAR": ILUSTRAR, PROPAGAR Y GOBERNAR LA PRENSA PERIÓDICA}

En la década de 1820, la libertad de imprenta aún no constituye una sección específica de los informes ministeriales, sino un párrafo dentro de la sección intitulada "Ilustración", "Ilustración general" o "Ilustración e Instrucción". Es a partir de la década de 1830 que amerita una sección autónoma (con excepción de la Memoria de 1838, que la incluye en la sección "Instrucción pública"), sección ya no exclusivamente subordinada a la ilustración o la educación del "pueblo". De paso, este sutil desliz erige una frontera entre la prensa "política" en un sentido partidista (es decir, la de oposición, principal blanco de la represión gubernativa) y la benéfica prensa indisociable de la Ilustración. En este último caso, la imprenta es constantemente mencionada como la herramienta por excelencia para impulsar el "progreso", verdadera religión del periodo que une a los "periodistas" 
o "publicistas", polígrafos y a la vez agentes o actores políticos, literatos o "historiadores".

Junto con la "instrucción pública", la libertad de imprenta, o mejor dicho el fomento de la imprenta y de la prensa periódica, se relaciona con la formación y la construcción de la sociedad política y de la clase gobernante, única "opinión pública" valiosa. En este periodo, lo mencionamos, la prensa periódica no es ni masiva ni popular: se dirige a una vaga y restringida élite letrada y económica, que se busca ampliar, así como a intermediarios y gestores de multitud (funcionarios públicos, juristas, maestros, comerciantes y empresarios...). Más allá de los mensajes partidistas, la función periodística tiene como objeto transformar a la sociedad, al difundir "instrucción" y "conocimientos útiles". Son notables en este sentido las reglamentaciones de imprenta de 1846 y 1855, ambas firmadas por Lafragua, quien constantemente reafirma la misión sagrada de la libertad de prensa, que consiste en "derramar los conocimientos, única base de la felicidad pública", "derramar el germen de la civilización en las clases menos adelantadas", o "derramar por todas partes el germen de la virtud", es decir, "establecer por donde quiera los principios de la justicia y hacer la felicidad de las naciones con los inmensos beneficios de la civilización". ${ }^{29}$ De modo que la "ilustración" corresponde no solamente al ideario del siglo xvIII, sino también a la estrategia dieciochesca de su "propagación"; es decir, el difusionismo, dinámica centralista o "descendiente" -desde un centro dominante hacia la periferia o la base-, y práctica "civilizadora" que recorre todo el siglo xIx.

En los años de 1820-1830, el establecimiento de la imprenta y de la prensa periódica en la provincia, donde no existían en la década anterior, se debe esencialmente a iniciativas de las nuevas

${ }^{29}$ Véanse las circulares dirigidas por José María Lafragua a los gobernadores de los estados, Diario del Gobierno de la República Mexicana (19 nov. 1846), p. 2, y El Siglo Diez y Nueve (30 dic. 1855), pp. 2-3. 
autoridades políticas, que introducen el arte tipográfico y publican los primeros periódicos, entonces oficiales u oficiosos. En 1822, esta estrategia se refleja en la Memoria de José Manuel Herrera, ministro durante la primera Regencia, que invoca a la tradicional lucha contra "las tinieblas de la ignorancia" y señala que "por una y otra vez se han expedido circulares excitando a los Ayuntamientos de las capitales de Provincia donde no había imprentas, para que se las procuren [...] y no carezcan de este órgano tan apreciable y aun necesario para el fomento y propagación de las luces". ${ }^{30}$ En 1826, el informe ministerial de Sebastián Camacho lamenta los "funestos extravíos" de la imprenta y los abusos de la libertad de prensa que prosperan por la ineficiente aplicación de las leyes y "la falta de educación", pero al mismo tiempo celebra los múltiples avances realizados, al declarar: "los periódicos se han multiplicado con buen suceso, y a proporción, el establecimiento de las imprentas". ${ }^{31}$ Sin multiplicar los ejemplos, limitémonos a subrayar que tal apología del "sublime" arte tipográfico y de sus benéficos provechos, en tanto que medio poderoso y eficaz del "progreso", constituye un discurso no exento de ilusión lírica, omnipresente y duradero, tanto en los discursos oficiales como en la prensa periódica.

Florecen entonces -en particular desde los años de 18301840- las revistas llamadas "literarias" o culturales, que no se dedican exclusivamente a la literatura, sino también a la elaboración y la difusión de una identidad y una memoria nacional; revistas a menudo favorecidas o fomentadas por el propio gobierno. Tales empresas ministeriales se observan en la promoción de una "literatura nacional", que incluye "las ciencias y las artes" (es decir, las modernas tecnologías), mediante la publicación de suplementos al periódico oficial, como son el

30 Ministerio de Relaciones, Memoria, 1822, pp. 11-12 ("Sección de Fomento").

31 Ministerio de Relaciones, Memoria, 1826, pp. 22-23. 
Registro Trimestre (1832) o la Revista Mexicana (1835); todas iniciativas orgullosamente anunciadas por los ministros, inmediatamente anteriores a las conocidas y lujosas empresas privadas de la misma índole, como son El Mosaico Mexicano (1836-1837, 1840-1842) o El Museo Mexicano (1843-1845). ${ }^{32}$ No cabe duda de que los intereses gubernamentales coinciden con las nacientes "casas editoriales", es decir, entre otras, las imprentas de Ignacio Cumplido o de Vicente García Torres, empresas privadas cuya supervivencia económica depende también de los pedidos oficiales. De hecho, la evolución acelerada de la edición y de la prensa se encuentra ratificada e impulsada por el decreto del gobierno de 3 de diciembre de 1846, que establece la primera normatividad meramente mexicana en materia de "propiedad literaria" o derechos de autor; reglamento inmediatamente posterior a la ley general de imprenta de 14 de noviembre y elaborado por una "junta" integrada, entre otros miembros, por Cumplido y encabezada por Lafragua.

Cabe traer a colación los "gabinetes de lectura" mencionados en los informes ministeriales y a veces confundidos en la historiografía con el conocido e importante fenómeno europeo de la multiplicación de estos centros de lectura donde, mediante

${ }^{32}$ Las iniciativas ministeriales son mencionadas en las secciones "Prosperidad general" e "Instrucción pública" de los informes. Al anunciar la publicación del Registro Trimestre, "absolutamente independiente de las cuestiones políticas" y "destinado a materias de literatura y ciencias naturales, aplicadas éstas a las artes y manufacturas", Lucas Alamán concluye: "Mucho fruto debe esperarse de la afición que se generalizará a este género de conocimientos, haciéndolos por este medio populares, y poniéndolos al alcance de toda clase de lectores" (Ministerio de Relaciones, Memoria, 1832, p. 14). En cuanto a la Revista Mexicana, su contenido es sintetizado por el ministro José María Gutiérrez de Estrada, quien precisa: "se fomentará la ilustración [...]; se señalarán los adelantamientos que se hagan en todos los ramos; se advertirán los obstáculos que embaracen el progreso de nuestra industria; y el Gobierno espera que se cumplirán sus deseos de ver propagadas las luces, y disipados los errores que ejercen tan poderosa influencia en el atraso que sufrimos" (Ministerio de Relaciones, Memoria, 1835, p. 42). 
una suscripción, se puede leer libros y periódicos. No obstante, en México, son muy contados en la época, por no decir casi inexistentes: entre 1820 y 1855 , no se localizan más que cinco de estos centros de lectura en la capital, de los que sólo uno -que fracasa- data de 1820 y cuatro de la década de 1840. Para hablar del caso mexicano, se puede mencionar la Memoria de Lucas Alamán de 1823 o las afirmaciones de José María Luis Mora en El Indicador de la Federación Mejicana de 1833, según las cuales en todos los estados de la República "se han establecido imprentas, periódicos, escuelas de primeras letras, bibliotecas, gabinetes de lectura". ${ }^{33}$ Sin embargo, es necesario citar íntegramente el discurso del ministro y debatir acerca de las generalizaciones y fuentes -desconocidas-del "periodista” Mora. De modo que la existencia de gabinetes de lectura, mencionados en solamente tres Memorias, en 1823, 1825 y 1846, descansa en declaraciones que remiten a empresas institucionales, no privadas a la manera europea, y que esencialmente reflejan intenciones, no realidades.

En su Memoria de 1823, Alamán señala que "para facilitar la ilustración [de la nación], se ha mandado formar en todas las casas de Ayuntamientos un gabinete público de lectura”, y agrega:

[...] se ha encargado a los jefes políticos que exciten a los vecinos a contribuir mensualmente con sumas cortas al fomento de estos establecimientos, que podrán suscribirse entonces a periódicos y obras de utilidad general, como se ha efectuado ya en algunas capitales de provincia, y es de desear que se verifique en todas, pudiéndose considerar éste, como uno de los medios más adecuados para difundir las luces y adelantar el cultivo general.

Más allá de la retórica ilustrada, el ministro advierte que se trata de "poner a la vista de todos las providencias que se dictan,

33 Véase El Indicador de la Federación Mejicana del 4 de diciembre de 1833, reproducido en 1836 en Mora, Méjico, t. I, p. 88. 
a fin de que siendo mejor conocidas sean puntualmente ejecutadas", y que por ello son necesarios dichos gabinetes "públicos", "donde se hallen todas las ordenes y otros papeles circulados por el gobierno, de manera que todos puedan instruirse e informarse de ellos". ${ }^{34}$ Por otra parte, en su informe de 1825, el mismo Alamán reitera consideraciones idénticas pero admite que "este género de establecimientos no se [ha] extendido tanto cuanto era de desearse".${ }^{35}$ Después de un largo silencio, no es sino hasta 1846 cuando aparecen en un informe ministerial las últimas menciones de esta clase de gabinetes institucionales. En primer lugar, es para proponer que se establezcan "pequeños gabinetes de lectura para los artesanos y demás personas poco acomodadas”, con el objetivo, precisa José María Lafragua, de derramar "poco a poco los conocimientos útiles en toda la sociedad" y de "fomentar la ilustración", y esperando que "nuestros artesanos al salir de sus talleres, se dirijan a un gabinete de lectura en vez de tomar el camino de la taberna". En segundo lugar-esta vez, en la sección "Policía de seguridad / Medios preventivos"-, Lafragua reitera su propuesta de instituir gabinetes para artesanos, con la meta de desarrollar "la curiosidad y la afición a la lectura" y de "difundir el gusto por los periódicos"; dichos gabinetes sirviendo "cuando menos de un medio de evitar la vagancia que es la fuente más abundante de los delitos". En todo caso, el ministro precisa que "la escasez de fondos y la falta de tiempo le impidieron realizar esta idea". ${ }^{36}$

La difusión de la "Ilustración" y de cierta modernización, la voluntad de ratificar o rectificar normas y valores, así como de ampliar la estrecha sociedad política, se encuentran entrelazadas con una multitud de problemáticas, primeramente

34 Ministerio de Relaciones, Memoria, s. f. [1823], pp. 39-40. Redactada en el mismo tenor, la circular de Alamán, con fecha de 25 de junio de 1823, precisa que los gabinetes serían gratis para los lectores.

35 Ministerio de Relaciones, Memoria, s. f. [1825], p. 37.

36 Ministerio de Relaciones, Memoria, 1847, pp. 120 y 131. 
con la cuestión educativa, preocupación continua de todos los gobiernos. En ello destaca la clásica disyuntiva acerca de la indispensable "formación" de un pueblo heterogéneo y poco educado, previa a la generalización de la ciudadanía y acorde con los proyectos económicos de índole liberal. Recordemos que la promoción del "progreso" intelectual, moral y político, es entonces indisociable del progreso material y del "espíritu de empresa”. En enero de 1861, pocos días antes de poner en vigor el nuevo reglamento de imprenta, Zarco expone claramente este notorio lineamiento en una circular dirigida a los gobernadores de los estados para presentar el "Programa de la administración” de Benito Juárez: el gobierno está persuadido, dice el ministro, de que "con la libertad el periodismo puede llegar a ser un elemento de civilización y de progreso, y que en su libertad no solo se interesan los derechos políticos, sino el comercio y la industria, el trabajo y el capital, la ciencia y la literatura". ${ }^{37}$

Además de estas conocidas perspectivas, sobresalen el papel central y la dimensión organizativa de la prensa periódica -no del libro-, en particular la prensa oficial u oficialista que concentra la atención del gobierno. Así como lo señala en 1835 el ministro José María Gutiérrez de Estrada: "Los periódicos suplen los conocimientos y los libros que el mayor número de la sociedad no tiene tiempo ni medios de adquirir". ${ }^{38}$ Varios de estos aspectos se encuentran sintetizados en una circular de 1856, dirigida a los gobernadores y firmada por Lafragua, ministro de Gobernación, que ordena fijar en los parajes públicos el periódico oficial de su estado para "promover la instrucción del pueblo", "hacer que el pueblo lea los periódicos, que en todos países civilizados se consideran como un poderoso agente para generalizar la ilustración y formar el espíritu público",

37 Circular de 20 de enero de 1861, firmada por Francisco Zarco, Secretaría de Estado y del Despacho de Relaciones Exteriores, El Siglo Diez y Nueve (31 ene. 1861), p. 2.

38 Ministerio de Relaciones, Memoria, 1835, p. 42. 
que "todos los habitantes de la república estén impuestos de la marcha que sigue su administración”, que "la opinión pública se uniforme y que las ideas del pueblo no sean extraviadas por las falsas especies que intencionalmente esparcen los enemigos de la libertad". ${ }^{39}$ De este modo, "espíritu público” y "opinión pública” -en singular-, que se deben formar y uniformizar, están estrechamente ligados con la promoción de la cohesión social y nacional, y de la "tranquilidad pública” en una nación indivisible; unión, “orden público” o "paz pública” que todos los informes ministeriales y las leyes de imprenta procuran fomentar.

Lo mencionamos, la fiscalización de escritos contrarios a la "moral" o las "buenas costumbres", efectiva en todos los reglamentos generales de imprenta, se relaciona con la cuestión de la cohesión social y nacional. Se inscribe en esta misma problemática la continua denuncia de la calumnia y la difamación, enfoques de la Ley Otero de 1848 que también se puede usar para neutralizar las críticas a las distintas autoridades. Tal constante inquietud corresponde también al deseo de afianzar nuevos códigos de hábitos y de conductas sociales y políticas, es decir, "reformas sociales" y culturales, en un proceso civilizatorio indisociable del arraigo en el inmenso territorio nacional de la autoridad política, federal o central, y de su legitimidad. Estos últimos aspectos constituyen otra notable continuidad en los informes ministeriales y en todas las normas reguladoras de la prensa, que erigen en delito de imprenta la incitación a desobedecer alguna ley o "autoridad legítima" o "constituida”, de manera directa o indirecta. La Ley Lares de 1853 merece especial mención, al agregar a estos “abusos" el hecho de atacar "a los actos” del Poder Ejecutivo y de insultar "el decoro del gobierno supremo, del consejo o de cualquiera autoridad

39 Legislación, pp. 530-531. 
superior o inferior" ${ }^{40}$ Por su parte, inspirado por el anterior, el Reglamento Lafragua de 1855 implanta el inédito delito de "irrespetuosidad", al estipular que "los actos oficiales de funcionarios son censurables, mas nunca sus personas", y que "será, pues, abuso de la libertad de imprenta la censura de las personas en cualquier caso, y la de los actos oficiales en el de hacerse en términos irrespetuosos o ridiculizando el acto" ${ }^{41}$ La Ley Zarco de 1861, que protege "la paz pública", no prohíbe la incitación a la desobediencia, pero la suspensión de garantías en el mismo año posterga su aplicación hasta 1868.

Junto con cierta mística de la Ilustración, la publicidad de las acciones gubernativas y el arraigo del joven y frágil Estado, a menudo confundido en los discursos ministeriales con el gobierno, constituyen el papel ideal de los periódicos. En 1844, el informe de José María de Bocanegra, ministro del presidente Antonio López de Santa Anna, justifica la represión gubernativa de los periódicos "perniciosos", a los que opone una libertad de imprenta "bien entendida"; ésta, alega el ministro, "infunde respeto a las leyes", "es útil, es benéfica, y hace sentir una virtud inefable y consoladora en tal grado que afianza los gobiernos, los hace subsistir" ${ }^{42}$ Un año después, Luis G. Cuevas, ministro del presidente Joaquín de Herrera, presenta una Memoria enteramente dedicada a fustigar la dictadura del gobierno anterior y, si bien rinde homenaje a la prensa, "único medio de comunicación, que aunque débil, oponía alguna resistencia provechosa y legal a los avances que se proyectaban", el ministro suspira:

\footnotetext{
40 Artículo 23, Dublán y Lozano, Legislación, t. VI, 1877, núm. 3811, p. 371. 41 Artículo 4, Dublán y Lozano, Legislación, t. VII, 1877, núm. 4600, p. 633. En este reglamento, el impreso "irrespetuoso" produce la misma pena que el escrito "contrario a las buenas costumbres" (artículo 13). Tal inédito "abuso" de la libertad de imprenta se encuentra reiterado en la ley imperial de 1865.

${ }^{42}$ Ministerio de Relaciones, Memoria, 1844, pp. 65-66.
} 
La literatura, las ciencias, las artes, no han podido florecer como debieran, porque el talento no se cultiva sino en medio de ese reposo general que distrae el ánimo de ocupaciones penosas, y de la inquietud en que frecuentemente se vive durante los periodos de agitación. [...] La tribuna parlamentaria, la imprenta, la discusión pública, son los medios más adecuados para que el ciudadano que merezca figurar ocupe el rango a que lo destina o su ilustración o sus virtudes. ${ }^{43}$

De hecho, en 1849, el mismo Cuevas reconoce que "la verdadera libertad de imprenta es el fanal de la civilización, el escudo impenetrable contra la arbitrariedad del poder, el mejor auxiliar de las reformas sociales y el medio más seguro del dominio de la razón y de las luces sobre la fuerza física”, ${ }^{44}$ pero pronuncia el alegato más extenso y severo contra la "licencia de la imprenta” y su "impunidad”. Arraigar la autoridad del Estado a nivel nacional, conquistar el espacio público de comunicación y guiar a la sociedad, todo ello por medio del impreso y de voceros "racionales", he aquí el programa de la libertad de prensa compartido por el conjunto de la clase política.

Al lado de estas perspectivas fundamentales, el objeto manifiesto de las normas reguladoras de la prensa, y sobre todo de las numerosas medidas circunstanciales, remite a la voluntad de contener las contiendas periodísticas de la vida política y a la vez de domar el escandaloso y turbulento espacio público urbano. Sin lugar a dudas, la "licencia” de la prensa -sus excesos- y la "anarquía” general, invariablemente presentada como su corolario, constituyen el leitmotiv clásico de las quejas oficiales que ofrecen una idéntica letanía acerca de los “abusos” de la libertad de imprenta, y es en general para denunciar a los oponentes políticos. La descalificación de la prensa en los informes

43 Ministerio de Relaciones, Memoria, s. f. [1845], pp. 98 y 125.

44 Ministerio de Relaciones, Memoria, 1849, p. 25. 
ministeriales, que describen un Estado eternamente sitiado por los periódicos, revela un primer criterio que consiste en confundir gobierno y Estado, y enlazar la suerte de los gobernantes en turno con la del país. Derivado de ello, otro mecanismo consiste en imputar las crisis, la división y el caos a la prensa periódica, en un discurso maniqueo y alarmista, en todo caso partidista, que oculta las múltiples causas de la inestabilidad institucional y de la ingobernabilidad.

Más allá del catálogo de los "abusos" de imprenta, cuyas jerarquía, calificación y sanción varían de acuerdo con las contingencias políticas y las estrategias puntuales, no cabe duda de que las normas legales tienden a convertir la represión en prevención -por no decir en censura previa- $\mathrm{y}$ a generar autocensura. Asimismo, es preciso recalcar cierto carácter indirecto de este control, enfocado no exclusivamente en los mensajes sino también en los vectores materiales de la producción, circulación y difusión impresa. Al igual que los discursos, su publicidad es particularmente temida por las autoridades y por ello objeto de múltiples medidas organizativas o represivas. Esto es, el control del voceo de papeles, de los vendedores y expendedores, de la fijación de impresos o carteles en el espacio público, y sobre todo de la imprenta y los impresores, y la delicada cuestión de su responsabilidad o "complicidad" con los autores. En 1832, Lucas Alamán tiene una solución "muy fácil” para remediar los abusos de imprenta, es decir, "reglamentando debidamente, no ya el uso de esta preciosa libertad, sino las condiciones que deben requerirse para el establecimiento de una imprenta, y para ejercer esta clase de industria". ${ }^{45}$ Desde la década de 1820 , las obligaciones de los impresores y su responsabilidad en los delitos de prensa son temas omnipresentes en las normas legales y muy recurrentes en las disposiciones circunstanciales, generando arrestos, destierros y cierres de talleres. En esta materia,

45 Ministerio de Relaciones, Memoria, 1832, p. 10. 
los vaivenes regulatorios y represivos son quizá los más numerosos. Producen controversias ruidosas, célebres causas y figuras emblemáticas del arte tipográfico, como son, por ejemplo, Cumplido o García Torres. Queda que las trabas a la industria tipográfica, en pleno desarrollo, entran en conflicto con los proyectos "progresistas" de los gobernantes y pueden resultar contraproducentes, en particular ante la intensa demanda de impresos por parte del gobierno.

Con toda obviedad, la prensa periódica es el principal blanco del control administrativo y jurídico de la imprenta. Lo observamos, la clase política es consciente no solo del potencial sino también del ascenso del periódico, medio de comunicación que utiliza de manera frenética cuando está en el poder o en la oposición. El propio Lafragua, en 1846 ministro eufórico acerca del progreso tipográfico, califica los periódicos de "ciegos defensores del gobierno, o ciegos partidarios de la oposición”, y lamenta: "aunque nos cueste alguna repugnancia confesarlo, es preciso decir con toda franqueza, que entre nosotros pocas veces han sido los periódicos los legítimos órganos de la opinión nacional". ${ }^{46}$ Es conocida la antigua y duradera práctica de subvención financiera oficial a empresas periodísticas, revistas "literarias" e "ilustradas", periódicos oficiales en tanto que plataforma propia y diarios "independientes", voceros políticos, auxiliares de campañas electorales y contrafuegos a la prensa crítica que provoca la cólera del gobierno. Asimismo, resulta característico el caso del moderno Lucas Alamán, favorable a la libertad de imprenta y quizá el más tenaz en la represión de sus "excesos", quien, sin embargo, descansa constantemente en la prensa para defender sus posturas y atacar a los grupos políticos rivales; por ejemplo, con el Registro Oficial del Gobierno de los Estados-Unidos Mexicanos en la década de 1830, más explícito y radical que sus posturas ministeriales públicas, con

46 Ministerio de Relaciones, Memoria, 1847, p. 174. 
El Tiempo de 1846, periódico promotor de la monarquía representativa, o con El Universal, órgano del partido conservador fundado en 1848. En 1853, poco antes de su muerte, el político dirige una famosa carta a Santa Anna, en la que formula lineamientos para el gobierno y precisa: "para realizar estas ideas se puede contar con la opinión general, que está decidida a favor de ellas, y que dirigimos por medio de los principales periódicos de la capital y de los estados, que todos son nuestros". ${ }^{47}$

Las contradicciones son flagrantes entre el persistente descrédito de la prensa en los discursos ministeriales y las prácticas periodísticas compartidas entre unos y otros grupos políticos. Sobre todo, dan cuenta de la duradera paradoja de las estrategias gubernamentales, que consisten en promover y a la vez reprimir las publicaciones periódicas; un equilibrio aún más difícil de mantener ante el significativo crecimiento periodístico. Es más, a partir de los años de 1840-1850, la periodicidad diaria, característica de la prensa crítica, se arraiga en el mercado periodístico de la ciudad de México. Esta sensible variación en el régimen de la "actualidad" se remite a una nueva economía del tiempo: tiempo presente, inmediato, tiempo conflictivo de alerta continua. Tal tendencia es perceptible en el informe de Luis Gonzaga Cuevas, quien, en 1849, fustiga "la clase de hombres que no son capaces de dirigir la opinión pública” y distingue "los pocos periódicos y escritos sensatos" de los desprestigiados "diarios", asemejados a "la colección de libelos difamatorios de que está infestada la República”. ${ }^{48}$ Ante la multiplicación de impresos, el ritmo acelerado de las publicaciones periódicas y su capacidad de intervención rápida, las estrategias controladoras, preventivas y represivas, siempre provisionales, también expresan cierta impotencia del gobierno en turno. A la mitad

47 Carta de Lucas Alamán a Antonio López de Santa Anna, 23 de marzo de 1853, en Lira, Lucas Alamán, p. 353.

48 Ministerio de Relaciones, Memoria, 1849, pp. 25-26. 
del siglo, es significativa, en este sentido, la Ley Lares, único reglamento decimonónico que, en un título específico, siente la necesidad de definir legalmente los distintos impresos para enfocarse en los periódicos. Más allá de la "obra", el "folleto" y la "hoja suelta", cuyas características son exclusivamente formales y merecen poca atención, la ley identifica el "periódico" con base en criterios de periodicidad y de contenido; es decir: "todo impreso que se publique en épocas o plazos determinados o inciertos, que trate de materias políticas o de administración pública". ${ }^{49}$ Claramente, la legislación se polariza en el impreso periódico en tanto que "político". De hecho, esta misma ley, que instituye por primera vez la figura del "editor-responsable", establece la obligación para este último de realizar un "depósito" pecuniario previo a la publicación -o fianza previa- de periódicos exclusivamente "políticos", medida prohibitiva para las empresas periodísticas de modesta inversión financiera. Ahora bien, de manera general, el diario (cotidiano) tiende a desarrollarse en tiempos de crisis aguda, pero no predomina en la oferta periodística. ${ }^{50}$ Más numerosos, los semanales o bisemanales no refieren una actualidad en sincronía con acontecimientos puntuales: se trata de revistas "literarias" o "culturales", empresas didácticas y pedagógicas, en todo caso ideológicas, representativas de la edificación y difusión de esta Ilustración "nacional" arriba mencionada, en una suerte de transición lenta y pacífica, anhelada por todos los gobiernos.

Una serie de tres gráficas permite visualizar y confrontar las dinámicas entre las fundaciones y los ceses de periódicos en la

${ }^{49}$ Ley Lares, título II ("De la diversa clase de impresos y de su publicación"), artículo 9, Dublán y Lozano, Legislación, t. VI, 1877, núm. 3811, p. 370. El periódico ocupa 9 de los 13 artículos del título II.

${ }^{50}$ Entre 1822 y 1855, prevalecen en la capital los semanales (29\% de las fundaciones periodísticas cuyas periodicidades son conocidas), seguidos por los bisemanales, publicados dos veces a la semana (20\%), y los diarios (16\%). Acerca del arraigo del diario, véase Coudart, "El Diario". 
ciudad de México, las publicaciones de folletos y el número de disposiciones reguladoras de la prensa entre septiembre de 1821 y 1865 (véanse las gráficas en el Anexo). ${ }^{51}$ Ciertamente estas últimas impactan las publicaciones periodísticas de la capital, que se caracterizan por ser efímeras y ocasionales: $76 \%$ de éstas no sobreviven más de un año y $87 \%$ no rebasan dos años de existencia. Sin embargo, otros factores intervienen en esta inestabilidad, como son en primer lugar el evidente carácter circunstancial y reactivo de una prensa política y partidista, pero también la falta de lectores directos (analfabetismo y altos precios de los impresos) así como los problemas económicos y tecnológicos (altos costos de producción, carestía de materias primas o comunicaciones deficientes). En todo caso, por quinquenio - pero también anualmente-, los números casi idénticos de fundaciones y de ceses permiten también vislumbrar un género impreso siempre renaciendo de sus cenizas. La regulación continua o errática genera supresiones o suspensiones de periódicos, pero no detiene el inexorable desarrollo de la prensa durante el periodo. De hecho, el renuevo de disposiciones legales en los años de 1840-1850 y la concentración de las reglamentaciones generales a partir de este periodo, junto con la exacerbación represiva gubernativa, coinciden con la peculiar inestabilidad política y el desarrollo de la prensa periódica. Tal coincidencia cronológica da cuenta de la consolidación del género periodístico que parece rebasar las expectativas gubernamentales.

${ }^{51}$ Gráficas elaboradas con base en mi investigación sobre múltiples compilaciones de leyes decimonónicas mexicanas y periódicos del periodo, así como en los catálogos de Castro y Curiel, Publicaciones, y de Giron et al., Folletería. Si bien el criterio temporal quinquenal es artificial y arbitrario, permite una mejor legibilidad de las articulaciones generales entre las tres gráficas. Por lo que concierne a los periódicos capitalinos, el periodo 1822-1855 corresponde al corte temporal de los inventarios hemerográficos más completos -pero no exhaustivos- para la ciudad de México, y no toma en cuenta las desapariciones, reapariciones y cambios de título del periódico oficial. 
Las tendencias exactamente inversas de la evolución de la prensa periódica y la de la folletería (opúsculos, hojas sueltas y volantes, pasquines y libelos) señalan la complementariedad de estos dos géneros impresos. Para las décadas de 1820 y 1830 , la guerra gubernamental librada contra los panfletos favorece al periódico, en particular gracias a la ley contra los "libelos infamatorios" de 14 de mayo de 1831, que significa una ruptura en el sistema editorial a expensas de los panfletos, menos controlables que la prensa periódica y dominantes desde los inicios de la Independencia. Para las décadas de 1840-1850, sin embargo, en tiempos de aguda censura, renacen panfletos y libelos, género abominado por la clase gobernante, mas no siempre por el conjunto de la clase política. Así como lo escribe en 1857 Francisco Zarco, en un artículo editorial en favor de la libertad de prensa: "Cuando muere el periodismo, los gusanos de su tumba son el pasquín, el anónimo, el libelo clandestino". ${ }^{52}$ En este mismo periodo, y gracias también a la difusión de la nueva tecnología litográfica, surgen los precursores de la caricatura meramente periodística, género que conoce un notable y duradero crecimiento, expresión del renacimiento panfletista, esta vez gráfico. ${ }^{53}$ Cabe agregar que durante el Imperio, entre 1864 y junio de 1867 (periodo no representado en las gráficas), cuando se da cierta decaída de la producción de folletos, las fundaciones de periódicos capitalinos conocen una peculiar dinámica semejante a la del periodo 1841-1845. Estas articulaciones nos hablan así de la complejidad del sistema de información y comunicación impresa.

52 “Las restricciones a la libertad de la prensa”, El Siglo Diez y Nueve (30 oct. 1857), pp. 1-2.

53 Tal evolución se encuentra ratificada en la Ley Lares de 1853, que por primera vez en la legislación nacional menciona la caricatura, inquietud igualmente presente en todas las leyes posteriores. 
En la primera mitad del siglo XIX, que inaugura un periodo de vertiginoso desarrollo del impreso, la comunicación y la esfera pública periodística se encuentran en fase de construcción, proceso que en realidad se desenvuelve desde finales del siglo Xviır. Estamos en los orígenes de la era mediática, cuando el periódico acompaña la edificación del Estado nacional y deviene cimiento de la sociedad política y letrada que se busca ampliar. Bien vale reiterar que el género periodístico no se extiende todavía a la sociedad civil en su conjunto y no se puede considerar medio de comunicación masivo. Durante la primera etapa nacional, muchos de los animadores o agentes de la prensa son a la vez actores políticos que se alternan en el poder y usan las mismas armas respecto del impreso. En lo tocante a la libertad de imprenta, las discrepancias parecen más estratégicas que ideológicas. El presente estudio no busca establecer un catálogo de los defensores de la causa liberal, conservadora, republicana o monárquica, menos aún cuando, al fin y al cabo, y rebasando las ilusiones líricas, la censura, garante de cierta cohesión social, nunca deja de existir. Al descansar en las reglamentaciones de libertad de imprenta y en los informes ministeriales, este recorrido da cuenta de la lógica gubernativa y permite vislumbrar varias permanencias, es decir, lo que une a la clase política, más que lo que la divide.

En primer lugar, la clase gobernante comparte duraderas paradojas, consistentes en afirmar y a la vez limitar el nuevo derecho sagrado de libertad de imprenta, y también promover y a la vez reprimir a la prensa. Junto con ello, se establece un lazo indisociable entre prensa y poder. Por una parte, los discursos programáticos, "ilustrados” y civilizatorios, evidencian la creencia de la clase política en el medio impreso para transformar a la sociedad. A su vez, esta constante postura da cuenta de cierto voluntarismo que permite aclarar la indiscutible contradicción entre el espectacular desarrollo periodístico y el débil número de 
lectores -directos- en los inicios del siglo xIx. Por otra parte, la permanente intervención gubernativa institucionaliza el moderno hábito mediático y hace del periódico una herramienta imprescindible. Al enfocarse en la prensa periódica, las numerosas normas reguladoras de la imprenta y disposiciones contingentes proclaman su auge.

Tal preeminencia de la prensa periódica ratifica un verdadero axioma de la censura, cuyo rigor se enfoca y se desplaza en función de los medios de comunicación que se encuentran en plena expansión, pero que todavía no son, si no "domados", por lo menos "domesticados" o "civilizados". En este periodo de transición, inaugurada por la abolición de la censura previa, los cánones establecidos en los reglamentos de imprenta-suerte de gramática de la libertad de expresión y de sus "buenos" usosrevelan que se trata no solamente de prohibir sino también de prevenir, y a la par de promover normas colectivas, otro axioma de la censura. Ahora bien, si las "prevenciones" reguladoras pueden generar una cultura de autocensura periodística, también pueden producir cierta malicia creativa e inventiva de los autores y editores para esquivar las prohibiciones o las presiones políticas, es decir, un nuevo orden del discurso periodístico, como es el caso, por ejemplo, en el desarrollo de la caricatura periodística. En todo caso, el conjunto de estas observaciones dice cuanto la censura es a la vez destrucción y construcción.

Las reglamentaciones y disposiciones legales dan cuenta de praxis y de experimentaciones. No se contentan con enunciar discursos prohibidos; también concentran su atención en los vectores de su transmisión y su publicidad, en particular los impresores. Tal atención se encuentra exacerbada en la Ley Lares de 1853, cuyo texto, sin preámbulo alguno, arranca, no con el clásico catálogo de los "abusos" de la imprenta, sino con las "obligaciones de los impresores". Si bien de cierta manera se diseña la organización del oficio tipográfico, la duradera y errática represión legal de los impresores, suerte de censura 
indirecta, deja una huella negativa por su carácter arbitrario y contraproducente. Asimismo, la inestabilidad política y la creciente centralización del poder federal desembocan en la institucionalización de dos dispositivos reguladores de la prensa, de largo y corto plazo; es decir, la coexistencia en la República, a partir de 1861 y todavía después de 1868, de la ley de 1861 para los tiempos de paz y -en virtud de decretos de suspensión de garantías- de la ley de 1855 (junto con el decreto de 3-5 de noviembre de 1857) para los tiempos de crisis. No cabe duda de que estos frutos de las experiencias del periodo son definitorios y determinan las modalidades de acción de los regímenes políticos posteriores a 1867 .

Resulta central la década de 1840, cuando el peculiar desarrollo cuantitativo y cualitativo de la prensa periódica, aun efímera e inestable, coincide con la tendencia a la centralización político-administrativa y cierto frenesí regulatorio. Entre las siete o nueve reglamentaciones generales del periodo, seis son implementadas entre 1846 y 1865 , y solo tres lo son en la década de 1820. En este último periodo, cuando rigen el primer sistema federal y la primacía del Congreso, la libertad de opinión y de expresión es exclusivamente regulada por los parlamentarios. Inauguradas en 1829, las facultades extraordinarias -entonces extra-constitucionales- otorgadas por el Congreso al Poder Ejecutivo permiten inmediatamente reprimir la prensa periódica, sin observancia de las garantías individuales ni respeto por la autonomía de los estados. Tal intervención del gobierno federal, finalmente autorizada constitucionalmente por las Bases de 1843, se cristaliza a la mitad del siglo en la Constitución de 1857, que confía a la Suprema Corte de Justicia la protección federal de las garantías individuales y a la vez fortalece la suspensión de dichas garantías, lo cual permite al Poder Ejecutivo evadir la autoridad del Poder Judicial.

Ahora bien, las publicaciones periódicas conocen su más importante desarrollo del siglo entre los finales de la década de 
1860 y los inicios de la de 1880 , en una etapa intensa en que el mercado periodístico -la oferta- se extiende de manera espectacular. Ello da cuenta de una dinámica constante, pese a los permanentes intentos gubernamentales por controlar los impresos. Más allá de la suspensión de garantías que se convierte en el modus operandi del Poder Ejecutivo, la inestabilidad de las normas reguladoras de la libertad de imprenta durante la primera etapa nacional constituye un elemento central de la duradera narrativa sobre la lucha entre la anarquía y la tiranía, entre la libertad y la dictadura. De modo que, cuando triunfa la República liberal, el gobierno enfrenta una nueva disyuntiva que consiste en controlar la prensa sin trastornar por completo y nuevamente la ley de imprenta vigente, es decir, la liberal y muy simbólica Ley Zarco de 1861. De hecho, durante la República Restaurada, y sobre todo el porfiriato, la prodigiosa extensión de la esfera pública impresa, particularmente en la provincia, va de la mano con una producción periodística muy diversa, más comercial y barata, o si se quiere más "popular” y "masiva”; prensa que la historiografía califica como más "informativa” que "opinativa” en un sentido político y partidista. Sin embargo, es preciso recordar que, al igual que la difusión de la Ilustración y de normas colectivas, la llamada "información” no está exenta de “opinión”.

\section{REFERENCIAS}

Aguilar Rivera, José Antonio, El manto liberal. Los poderes de emergencia en México, 1821-1876, México, Universidad Nacional Autónoma de México, 2001.

Andrews, Catherine, De Cádiz a Querétaro. Historiografía y bibliografía del constitucionalismo mexicano, México, Fondo de Cultura Económica, Centro de Investigación y Docencia Económicas, 2017.

Arnold, Linda, Política y justicia. La Suprema Corte mexicana (1824-1855), México, Universidad Nacional Autónoma de México, 1996. 
Castro, Miguel Ángel y Guadalupe Curiel (coords.), Publicaciones periódicas del siglo XIX: 1822-1855, México, Universidad Nacional Autónoma de México, 2000.

Coudart, Laurence, “El Diario de México y la era de la 'actualidad'”, en Martínez Luna (ed.), 2009, pp. 197-225.

COUDART, Laurence, “La regulación de la libertad de prensa (1863-1867)”, en Historia Mexicana, LXv: 2 (258) (oct.-dic. 2015), pp. 629-687.

Dublán, Manuel y José María Lozano (eds.), Legislación Mexicana o colección de las disposiciones legislativas expedidas desde la Independencia de la República, México, Imprenta del Comercio, 1876-1912, 58 volúmenes.

EsCRICHE, Joaquín, Diccionario razonado de legislación civil, penal, comercial y forense, o sea resumen de las leyes, usos, prácticas y costumbres, como asimismo de las doctrinas de los jurisconsultos, dispuesto por orden alfabético de materias, con la explicación de los términos del Derecho, Juan Rodríguez de San Miguel (citas del derecho, notas y adiciones), México, Impreso en la oficina de Galván a cargo de Mariano Arévalo, 1837.

Giron, Nicole et al., Folletería mexicana del siglo XIX, CD-ROM, México, Secretaría de Educación Pública, Conacyt, Instituto Mora, 2001.

GonzÁlez, María del Refugio, "Las transiciones jurídicas en México del siglo xix a la Revolución”, en GonzÁlez y López Ayllón (eds.), 1999, pp. $85-134$.

GonzÁlez, María del Refugio y Sergio López Ayllón (eds.), Transiciones y diseños institucionales, México, Universidad Nacional Autónoma de México, 1999.

Legislación Mejicana, o sea Colección completa de la leyes, decretos y circulares que se han expedido desde la consumación de la independencia, México, Imprenta de Juan R. Navarro, 1856.

Lira, Andrés, Lucas Alamán, México, Cal y Arena, 2012.

Martínez Luna, Esther (ed.), Bicentenario del Diario de México: Los albores de la cultura letrada en el México independiente, 1805-2005, México, Universidad Nacional Autónoma de México, 2009. 
McGowan, Gerald, Prensa y poder, 1854-1857: La revolución de Ayutla, El Congreso Constituyente, México, El Colegio de México, 1978.

Ministerio de Relaciones, Memoria presentada al Soberano Congreso Mexicano por el secretario de Estado y del Despacho de Relaciones Interiores y Exteriores [José Manuel Herrera], México, Oficina de Alejandro Valdés, impresor de Cámara del Imperio, 1822.

Ministerio de Relaciones, Memoria que el secretario de Estado y del despacho de Relaciones Esteriores e Interiores [Lucas Alamán] presenta al Soberano Congreso Constituyente sobre los negocios de la secretaría de su cargo, leída en la sesión de 8 de noviembre de 1823. Impresa de orden del Soberano Congreso, México, Imprenta del Supremo Gobierno, en Palacio, s. f. [1823].

Ministerio de ReLaciones, Memoria presentada a las dos cámaras del congreso general de la federación, por el secretario de Estado y del despacho de Relaciones Esteriores e Interiores [Lucas Alamán], al abrirse las sesiones del año de 1825. Sobre el estado de los negocios de su ramo, México, Imprenta del Supremo Gobierno de los Estados Unidos Mexicanos en Palacio, s. f. [1825].

Ministerio de Relaciones, Memoria de los ramos del Ministerio de Relaciones Interiores y Esteriores de la República [Sebastián Camacho], leída en las cámaras del soberano congreso en los días 9 y 14 de enero del año 1826, México, Imprenta del Supremo Gobierno, 1826.

Ministerio de Relaciones, Memoria del Ministerio de Relaciones Interiores y Esteriores de la República Mexicana [Juan José Espinosa de los Monteros]. Leida en la Cámara de Diputados el 10, y en la de Senadores el 12 de Enero de 1827, México, Imprenta del Supremo Gobierno, en Palacio, 1827.

Ministerio de Relaciones, Memoria de la Secretaría de Estado y del Despacho de Relaciones Interiores y Exteriores, leida por el Secretario del ramo [Lucas Alamán] en la Cámara de Diputados el día 12 de febrero de 1830, y en la de Senadores el día 13 del mismo, México, Imprenta del Águila, dirigida por José Ximeno, 1830.

Ministerio de Relaciones, Memoria de la Secretaría de Estado y del Despacho de Relaciones Interiores y Exteriores [Lucas Alamán], Presentada por el Secretario del ramo, en cumplimiento del artículo 120 de la Constitución, a las Cámaras del Congreso general al principio de sus sesiones ordinarias del año de 1832, México, Imprenta del Águila, dirigida por José Ximeno, 1832. 
Ministerio de Relaciones, Memoria de la secretaría de Estado y del Despacho de Relaciones Interiores y Exteriores, Presentada por el Secretario del ramo [José María Gutiérrez de Estrada] a las Cámaras del Congreso general, en cumplimiento del artículo 120 de la Constitución, y leída en la de Diputados el día 26, y en la de Senadores el 30 de Marzo de 1835, México, Imprenta del Águila, dirigida por José Ximeno, 1835.

Ministerio de lo Interior, Memoria del Ministerio de lo Interior de la República Mexicana [José Antonio Romero], Leída en las Cámaras de su Congreso General en el mes de enero de 1838, México, Imprenta del Águila, dirigida por José Ximeno, 1838.

Ministerio de Relaciones, Memoria del Secretario de Estado y del Despacho de Relaciones Esteriores y Gobernación de la República Mexicana [José María de Bocanegra], correspondiente a la administración provisional, en los años de 1841, 42 y 43, leída en las Cámaras del Congreso constitucional desde el día 12 al 17 de Enero de 1844, México, Imprenta de Vicente G. Torres, 1844.

Ministerio de Relaciones, Memoria del ministro de relaciones exteriores y gobernación [Luis G. Cuevas], leída en el Senado el 11 y en la Cámara de Diputados el 12 de marzo de 1845, México, Imprenta Litográfica y Tipográfica de I. Cumplido, s. f. [1845].

Ministerio de ReLaciones, Memoria de la primera secretaría de estado y del despacho de relaciones interiores y esteriores de los Estados-Unidos Mexicanos, leída al soberano congreso constituyente en los días 14, 15 y 16 de diciembre de 1846, por el ministro del ramo, C. José María Lafragua, México, Imprenta de Vicente García Torres, 1847.

Ministerio de Relaciones, Memoria del ministro de Relaciones Interiores y Esteriores D. Luis G. Cuevas, leída en la Cámara de Diputados el 5 , y en la de Senadores el 8 de Enero de 1849, México, Imprenta de Vicente García Torres, 1849.

Ministerio de Relaciones, Memoria del Ministerio de Relaciones Interiores y Exteriores [José María de Lacunza], leída al Congreso General en enero de 1850, México, Imprenta de la calle de Medinas núm. 6, 1850.

Ministerio de Relaciones, Memoria leída en las Cámaras en [enero de] 1851. Por el Secretario de Relaciones Interiores y Esteriores [José María de Lacunza], México, Imprenta de Vicente G. Torres, 1851. 
Mora, José María Luis, Méjico y sus revoluciones, París, Librería de Rosa, 1836.

Planes en la Nación Mexicana, 1808-1987, México, Senado de la República, El Colegio de México, 1987, 9 volúmenes.

Tena Ramírez, Felipe, "La suspensión de garantías y las facultades extraordinarias en el Derecho mexicano", en Estudios Jurídicos, 39 (2006) [conferencia sustentada en 1945], pp. 26-65.

Tena Ramírez, Felipe, Leyes fundamentales de México, 1808-2005, México, Porrúa, 2008 [25ª ed., $1^{a}$ ed. 1957].

Zarco, Francisco, Historia del Congreso Estraordinario Constituyente de 1856 y 1857. Estracto de todas sus sesiones y documentos parlamentarios de la época, México, Imprenta de Ignacio Cumplido, 1857, 2 volúmenes. 


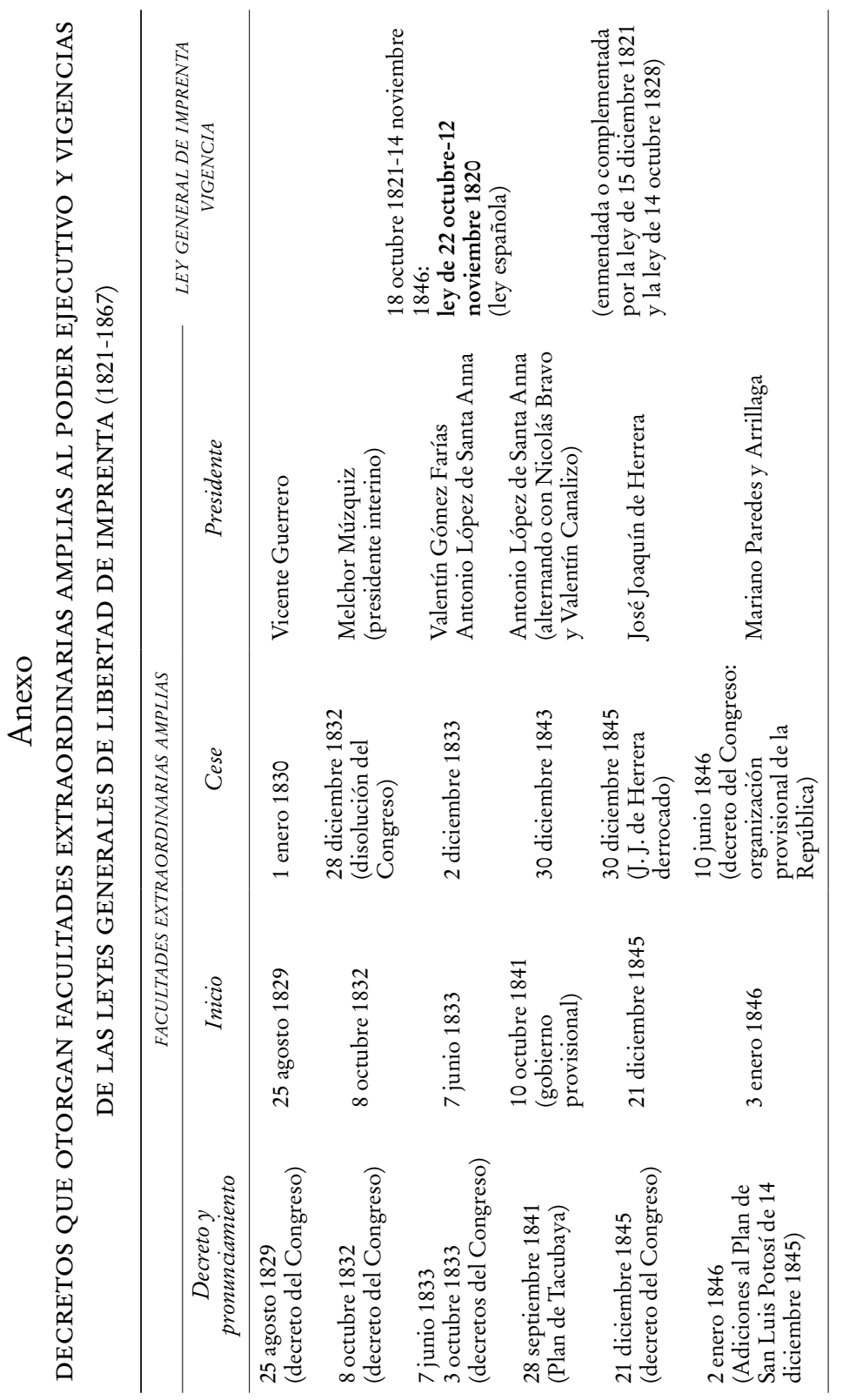




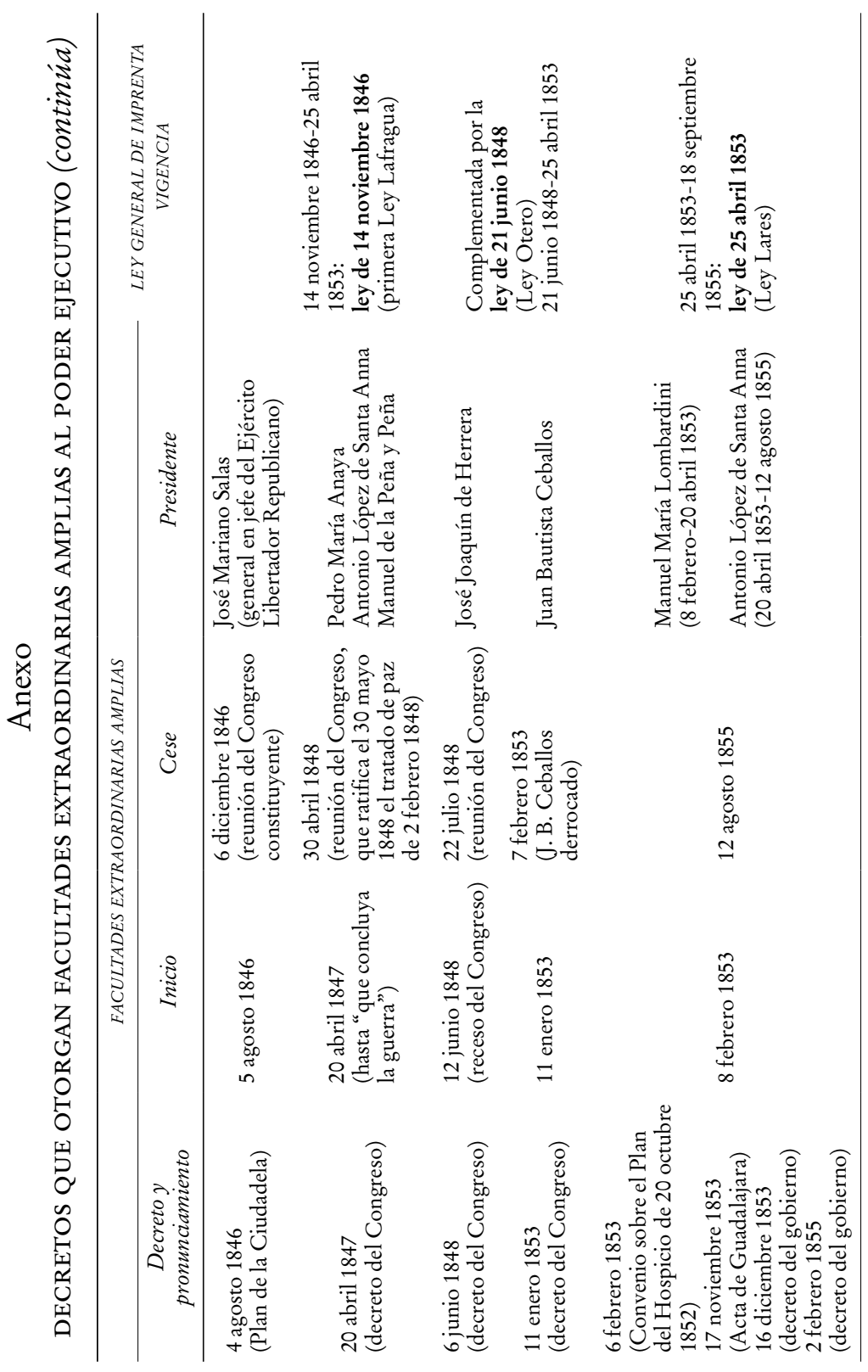



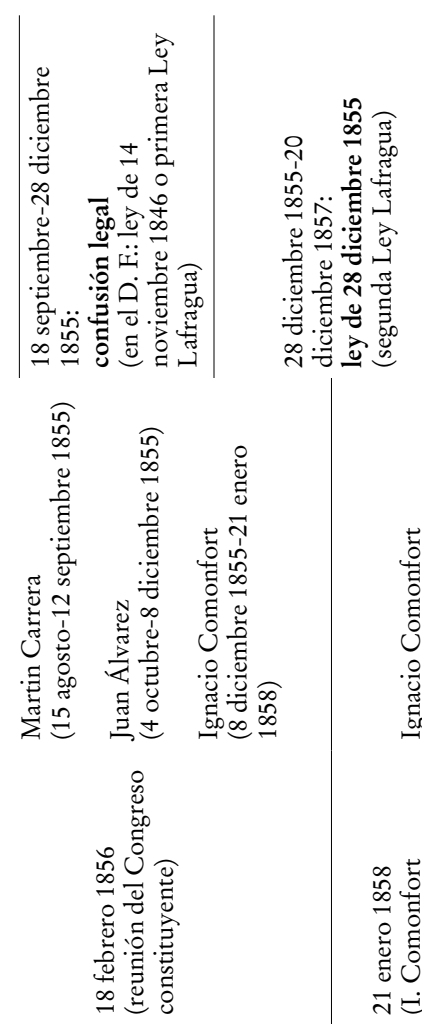

$n$
20
$\infty$
0
8
0
0
0
$\pi$
10

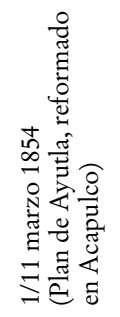

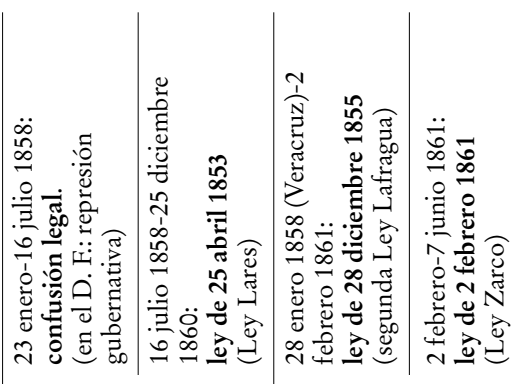
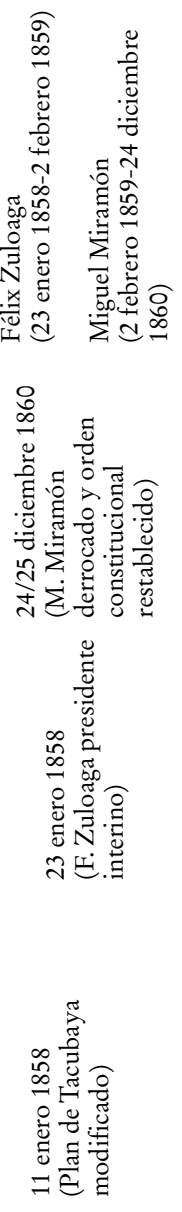

总

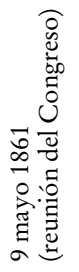

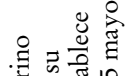

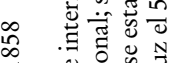

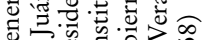
Әض்

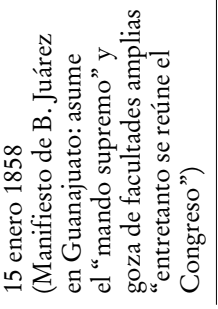

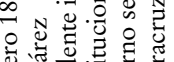




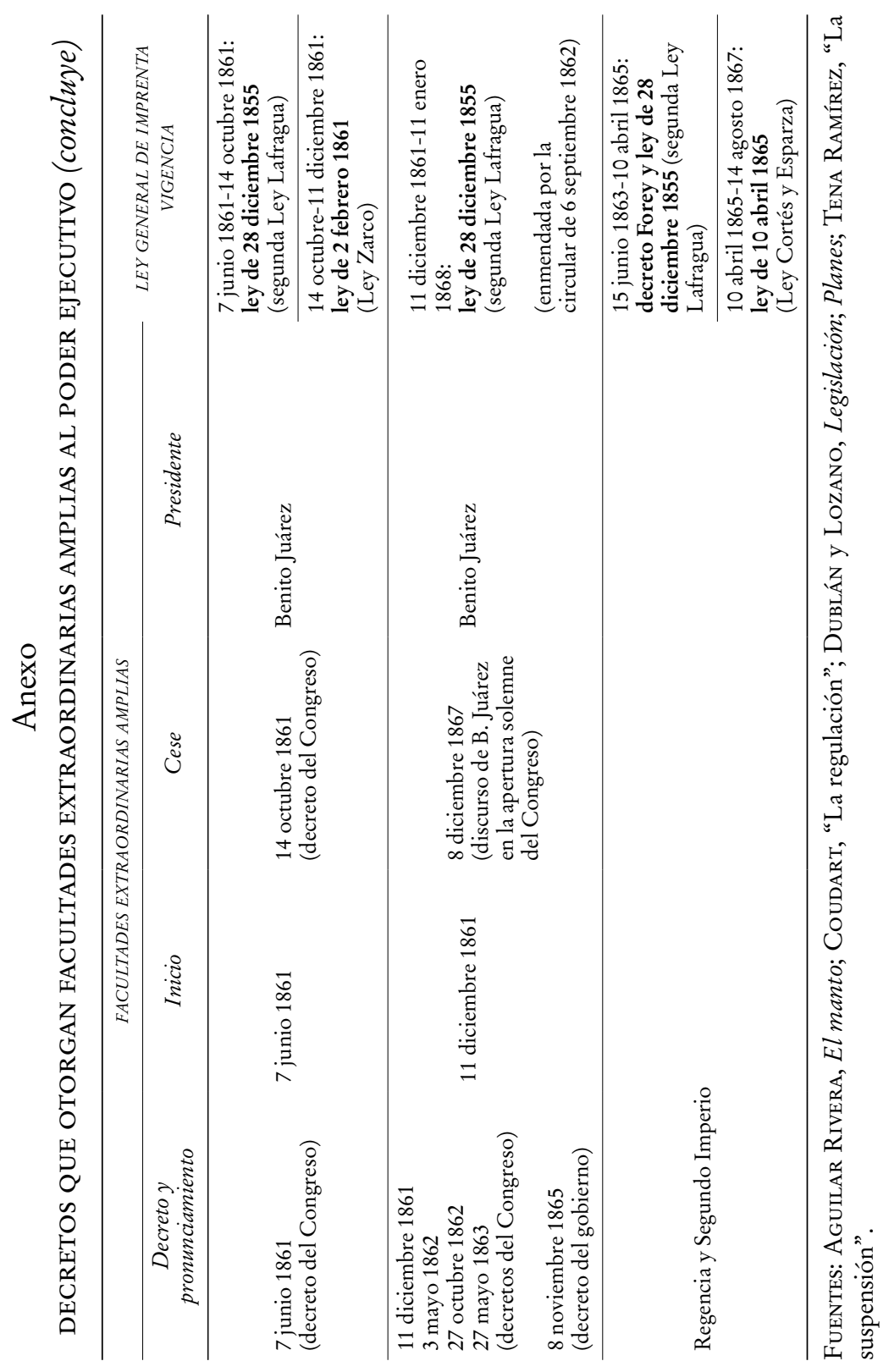


DISPOSICIONES LEGALES, PERIÓDICOS Y FOLLETOS (QUINQUENIOS, SEPTIEMBRE 1821-1865)

1. DISPOSICIONES REGLAMENTARIAS SOBRE LA LIBERTAD DE IMPRENTA, 1821-1865

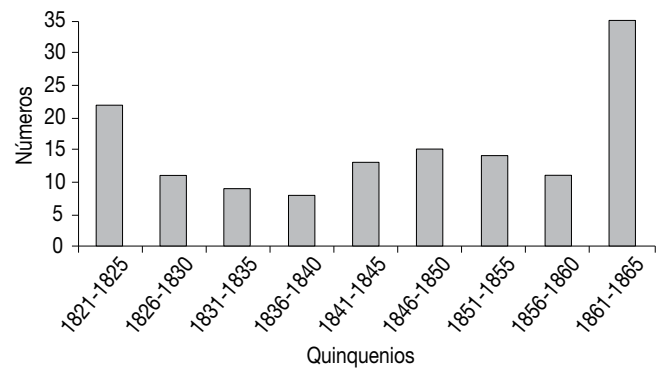

\section{FUNDACIONES Y CESES DE PERIÓDICOS} DE LA CIUDAD DE MÉXICO, 1822-1855

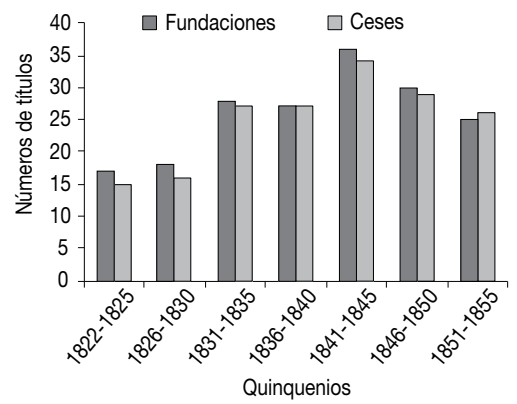

3. PUBLICACIONES DE FOLLETOS, 1822-1865

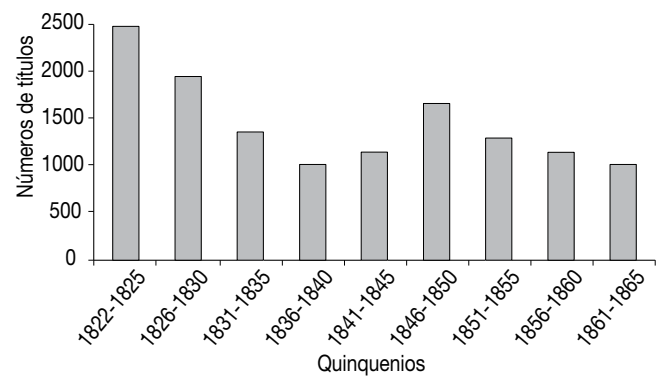


